\title{
Labour Unions - To Unite or to Separate?
}

\author{
THORSTEN UPMANN
}

CESIFO WORKING PAPER NO. 2413

CATEGORY 4: LABOUR MARKETS

OCTOBER 2008

\footnotetext{
An electronic version of the paper may be downloaded

- from the SSRN website: $\quad$ www.SSRN.com

- from the RePEc website: $\quad$ www.RePEc.org

- from the CESifo website: www.CESifo-group.org/wp
} 


\title{
Labour Unions - To Unite or to Separate?
}

\begin{abstract}
In this paper we investigate trade union formation. To this end we apply a model with two types of labour where the interests of both groups of labourers are represented by either a joint (industry) labour union or by two independent group-specific (professional) labour unions. We investigate whether, and if so, under which conditions, it is beneficial for at least one group of labourers to form its own independent union; or whether it is in the interest of both groups to have a joint industry labour union. Applying the (asymmetric) Nash bargaining solution, we find that under reasonable conditions, it is beneficial for at least one group of labourers to form its own independent labour union. In this case a joint union must be considered as an unstable institution. The profit share, however, is always higher if the firm bargains with a joint labour union. This explains why employers vehemently oppose recent split offs of specialized labour groups from existing industry unions and from tariff unions.
\end{abstract}

JEL Code: C78, J41, J51.

Keywords: trade-union formation, wage-employment bargains, Nash bargaining solution, industry and professional labour unions, trade union merger.

Thorsten Upmann

Institute of Mathematical Economics

University of Bielefeld

P.O. Box 100131

33501 Bielefeld

Germany

tupmann@wiwi.uni-bielefeld.de

August 10, 2008 


\section{Introduction}

Merger activity between labour unions ${ }^{1}$ has a long history in Western industrialized countries. A large number of mergers during the 20th century is documented by, for example, Chaison (1980) for the US, Griffin and Scarcebrook (1989) and Campling and Michelson (1997) for Australia, and by Buchanan (1974, 1981) and Waddington (1992) for the UK. For some countries, such as Australia, this trend has accelerated at the end of the century (compare Campling and Michelson, 1997). The structure of German labour unions has recently changed along similar lines. During the last years of the last millennium we observed a series of significant mergers of formerly independent labour unions. This series commenced with the unification of the IG Bau-Steine-Erden (IG BSE) and the Gewerkschaft Gartenbau, Land- und Forstwirtschaft to form the industry union IG Bauen-AgrarUmwelt (IG BAU) in January 1996. ${ }^{2}$ The next was the IG Bergbau, Chemie, Energie (IGBCE), which came into existence in 1997 through a merger of the IG Bergbau und Energie (IGBE) with the IG Chemie, Papier, Keramik (IGCPK) and the Gewerkschaft Leder (GL). In 1998 the labour union Gewerkschaft Textil und Bekleidung (GTB) joined the IG Metall, followed by the Gewerkschaft Holz und Kunststoff (GHK) in 2000. The most important merger, though, was the constitution of Verdi in 2001, which was a merger of five independent labour unions: Deutsche Angestellten-Gewerkschaft (DAG), Deutsche Postgewerkschaft (DPG), Gewerkschaft Handel, Banken und Versicherungen (HBV) and IG Medien, Gewerkschaft Öffentliche Dienste, Transport und Verkehr (ÖTV). ${ }^{3}$

The nature of the forces and the processes that lead to union mergers are varying and depend on the particular institutional context. ${ }^{4}$ Yet, irrespective of the underlying reasons and forces that led to, and the institutional framework that allowed for the realization of a particular merger, the concerned unions apparently spent a lot of money and effort in order to materialize the merger: Manifold obstacles must be surmounted and sometimes substantial opposition must be overcome before a new labour union could come into existence. In view of this effort spent in order to create large and arguably powerful (industry) labour unions, it is astonishing that, in Germany for example, during the last few years an opposite trend arose: 'Small' professional unions (craft unions), which formerly had tariff

\footnotetext{
${ }^{1}$ The notion 'union merger' is used very broadly and includes both consolidations and transfers of authority.

${ }^{2} \mathrm{IG}$ means Industriegewerkschaft, $i . e .$, industry union.

${ }^{3} \mathrm{At}$ the end of the year 2007 Verdi had 2.2 million members. The effects of the foundation of Verdi and the subsequent developments in the post-merger phase are documented and analysed by Keller (2005).

${ }^{4}$ Compare, for example, Morris (1986) and Campling and Michelson (1997).
} 
unions together with larger industry unions, fought for their right to negotiate independently with the employers. A notable example is the Vereinigung Cockpit (VC) which has become the recognized and established representative of the pilots in wage negotiations. Subsequently the physicians' association Marburger Bund negotiated for the first time for a separate wage agreement in 2006. And most recently, the engine drivers' association GDL (Gewerkschaft Deutscher Lokomotivführer) fought for almost 12 month with the Deutsche Bahn for a separate wage agreement. - Apparently, in any case the separating employees do not feel well backed by the representatives of the large industry union, and believe that they may negotiate for more than what they got in joint negotiations.

This raises the question which of the two strategies - building up joint, encompassing large labour unions, or the creation of small profession-specific unions consisting of a homogeneous membership — is actually in the labourers' (mutual) interest. Do the respective employees benefit from joint negotiations with the employer(s), or may some group of employees suffer from joint negotiations relative to what they could have obtained in autonomous negotiations? The documented recent tendency towards separate negotiations suggests that some groups of labourers, at least, have not benefited from joint negotiations, or believe that they can negotiate for more on a stand-alone basis. - In this paper we seek to shed some light onto this issue. To this end, we use a microeconomic bargaining approach with two types of labourers being imperfect substitutes in production.

We are, of course, not the first developing a model to scrutinize the effects of potential mergers (or separations) of trade unions, namely of profession-specific trade unions (craft unions) at firms' level. ${ }^{5}$ To our knowledge, Horn and Wolinsky (1988), Davidson (1988) and Dowrick $(1989,1993)$ were the first to analyse the effects of co-operation between different trade unions on negotiated wages and employment. With the exception of Dowrick (1989), who makes use of co-operative game theory, these authors apply Rubinstein's alternating-offer game to investigate the effects of trade-union centralization on labour market negotiations. While Horn and Wolinsky (1988) and Dowrick (1993) allow for varying degrees of complementarity and substitutability between the two types of labour, Davidson (1988) and Dowrick (1989) assume that production requires one type of homogeneous labour only. Starting from the work of Horn and Wolinsky (1988) who investigate the bargained wage contracts for a single firm, Davidson (1988) and Dowrick (1989,

\footnotetext{
${ }^{5}$ Mergers between trade unions may take place either along firms (of the same industry) and industries or along professions. In the first case a merger implies a centralization along the industry dimension; in the second case, along the dimension of profession. In the literature, the first mode of centralizations is frequently referred to as vertical centralization; the second, as horizontal centralization (cf., for example, Gürtzgen, 2003). Actual mergers frequently include both dimensions. For example, German trade unions merged along both industries and professions.
} 
1993) do so for either a duopoly or an oligopoly. Explicitly taking into account a firm's competitors allows for both output market effects and alternative patterns of unionization: the possibility of vertical centralization of trade unions (i.e., joint negotiations on behalf of labourers of different firms). More recently, Gürtzgen (2003) extends the analysis of Dowrick (1993) to multiple firms and various types of labour. Yet, this is done for the special case of a Leontieff technology, where there is no substitutability between different types of labour, thereby limiting the applicability of her results.

Although each of these contributions focuses on some other aspect of the topic, they have a common feature: All authors focus on equilibria on the labour demand curve. However, we know that, apart from the competitive equilibrium, allocations on the labour demand curve are not Pareto efficient. Thus, whilst these authors explore whether or not employees can do better by adjusting the organizational structure of trade unions, they ignore the possibility for Pareto improvements which may (simply) be realized by changing the agenda of negotiations with employers. Good arguments, positive and normative, can be made in favour of efficient labour market contracts. From a positive point of view, labour unions seldom have the power to dictate wages (monopolistic union), ${ }^{6}$ and labour unions and employers' associations typically do not bargain over wages alone (right-tomanage approach), but negotiate for working conditions, working times, workforce, job guarantees etc. as well. It is therefore reasonable to assume that unions and firms bargain, either directly or indirectly, about both wages and employment, rather than about wages alone. From a normative perspective, there is no reason why rational parties should relinquish any potential of mutual gains. Once they discover that there is some scope for mutual benefits, we should expect them to exhaust this potential; and if they won't, we should advise them to do so! In fact, even if there were evidence that the bulk of labour market conflicts is settled on the labour demand curve, the normative argument still applies - and thus calls for a thorough inspection of (axiomatic) solution concepts in the context of labour market negotiations.

On grounds of these arguments, we complement the theoretical literature on union mergers by using formal concepts of co-operative game theory to model efficient solutions of the labour market conflict. ${ }^{7}$ In particular, we assume that the employers' federation (firm) and the respective labour union bargain about

\footnotetext{
${ }^{6}$ Horn and Wolinsky (1988), p. 485f, criticize those who (simply) assume that unions are setting wages unilaterally rather than participating in some process of bargaining with the firm. We fully agree with this critique.

${ }^{7} \mathrm{~A}$ prerequisite for an application of co-operative game theory is that the underlying institutional framework guarantees that contracts are legally enforceable. But this premise can well be taken as granted in Western economies.
} 
both the wage rate and the employment level, and eventually settle their conflict according to the (asymmetric) Nash bargaining solution. ${ }^{8}$ Presuming this mode of settlement of the labour market conflict, we scrutinize the conditions under which horizontal trade union mergers may be favourable or unfavourable for the involved parties. This paper thus illuminates the structural features under which horizontal mergers may be expected to occur or may be regarded as stable (with respect to group specific split offs). In this sense the present paper proceeds along the lines of Horn and Wolinsky (1988) and Dowrick (1993) who focuses on possible co-operation between different craft unions at the firm (or industry) level.

\section{Outline}

In order to focus on the pure effects of labour-market negotiations between labour unions and an employers' federation, we abstract from non-labour factors of production and from any potential non-competitive behaviour on any market other than the labour market. We thus consider a competitive industry producing a homogeneous output, by means of two types of labour, which for expository purpose we call high- and low-skilled labour. In general, the interests of each group of workers may be represented by a corresponding group-specific, professional labour union. In this case the employers' federation (or the firm) has to negotiate about wages and employment with each labour union separately. As an alternative organizational scenario, we consider the possibility that both labourer groups unite and form an industry labour union acting on behalf of both groups' interest. Naturally, we should expect such a uniting to emerge only if this is beneficial for both groups of labourers. Similarly, we should expect a united labour union to break asunder if it is in the interest of, at least, one group to constitute a separate, independent labour union. We therefore contrast the outcome of the labour market negotiations between the firm and the two separate labour unions with the bargaining outcome when both labour groups form an industry union. In this way we are able to explore whether or not, and if so under which conditions, either of both groups faces an incentive to leave the joint labour union and to form a professional labour union. To this end we commence our analysis with the case where each group

${ }^{8}$ Efficient Nash bargains have been established in labour market economics by McDonald and Solow (1981), Creedy and McDonald (1991) and others, and have subsequently been applied by, for example, Bayındır-Upmann and Raith (2003, 2005), Boeters (2004) and Gerber and Upmann (2006).

It has well been recognized that different solution concepts may bring about diverging comparative static effects (compare, for example, Gerber and Upmann, 2006). It would thus not be surprising if the consequence of union mergers were to vary with the solution concept applied as well. Yet, it is beyond the scope of this paper to extend the analysis to a series of alternative solution concepts. This issue must thus remain open for future research. 
of workers is represented by a group-specific, or professional labour union, and proceed with the analysis of a joint, or industry labour union. Then we explore the stability of the two alternatives, that is, whether or not the coalition of the two groups of labourers can be expected to survive.

We find that a merger of two independent labour unions may give one group of labourers less than they would have achieved if they had negotiated separately; and this unfavourable effect may be dramatic: Although, we hold the institutional framework fixed (for example, the same solution concept is used before and after the merger), and we treat the situation between the two groups basically symmetric, it may happen that the bargaining outcome achieved under joint negotiations leaves one group of workers with the competitive wage and employment level. This outcome is clearly unsatisfactory for the respective group, since it would have obtained more under separate bargains. Specifically, if both labourer groups have the same bargaining power and firms use a Cobb-Douglas technology, at least one group of labourers benefits from remaining independent (or constituting its own professional labour union); and under full symmetry, this is true for both groups of labourers. Thus, joint bargains may even be unfavourable for both groups of labourers.

The driving forces behind this remarkable result are twofold. Firstly, since both groups of labourers aim at a higher wage and employment level, their interests are symmetric - and in this sense rival. This effect is further strengthened if the two types of labour are complements in production, for complementarity tends to provide each group with a greater effective bargaining power in separate negotiations. Secondly, the joint labour union may trade a higher welfare of one group for a lower welfare of the other. This process of substitution may eventually leave one group with its reservation utility: the competitive outcome. As a result, if the interests of both groups are parallel and the rationales for a merger thus coincide, a merger turns out to be more problematic. - This finding is also consistent with the empirical literature:

The data [...] could possibly indicate that, where the unions planning to merge share the same underlying motivations, the merger process is more likely to be problematic than cases of merger where the rational is quite different for each of the unions involved. (Campling and Michelson, 1997, p. 240.)

\section{The Model}

The group of high-skilled (low-skilled) workers consists of a total mass of $N_{H}\left(N_{L}\right)$ labourer households, all of which are assumed to have identical preferences. ${ }^{9}$ Each

\footnotetext{
${ }^{9}$ For ease of presentation we will speak of $N_{H}\left(N_{L}\right)$ laborer households in the following.
} 
household is either employed at the full regular working time or has no job at all. An employed household receives a wage income equal to the (real) wage $w_{i}$ and obtains a corresponding utility level of $u_{i}\left(w_{i}\right), i=H, L$, where $u_{i}: \mathbb{R}_{+} \rightarrow \mathbb{R}_{+}$is the representative household's utility function. An unemployed household, however, attains some fixed utility from the consumption of leisure and unemployment benefits, say $\bar{u}_{i}$. We assume that $u_{i}$ is twice continuously differentiable with $u_{i}^{\prime}>0, u_{i}^{\prime \prime}<0$, and that there exists some $\bar{w}_{i} \geq 0$ with $u_{i}\left(\bar{w}_{i}\right)=\bar{u}_{i}$. Hence, $\bar{w}_{i}:=u_{i}^{-1}\left(\bar{u}_{i}\right)$ is the reservation wage below which no household of type $i$ is willing to work. This implies that labor supply of group $i$ equals zero for all $w<\bar{w}_{i}$, equals $N_{i}$ for all $w>\bar{w}_{i}$, and is indeterminate, i.e., it is set-valued and equal to $\left[0, N_{i}\right]$ for $w=\bar{w}_{i}$. The interests of all workers, high- and low-skilled, are represented by either two labour unions or by one joint labour union, depending on the mode of organization of the work force. In any case, each labour union is assumed to act on behalf on its members' interest, maximizing the sum of its members' utilities.

On the other side of the labour market there is a firm, or an industry, producing its output by means of high- and low-skilled labour. Assuming that all other factors of production are fixed, these two types of labour are the only variable factors, and the production function may be written as $f: \mathbb{R}_{+}^{2} \rightarrow \mathbb{R}_{+}:(H, L) \mapsto$ $f(H, L)=Y$, where $H$ and $L$ denote the employment levels of high- and low-skilled labour, respectively. ${ }^{10}$ We assume that $f$ is twice continuously differentiable, with both types of labour possessing positive, $f_{H}, f_{L}>0$, but decreasing marginal products, $f_{H H}, f_{L L}<0$. (Subindices of $f$ denote partial derivatives.) Moreover, let $f(0, L)=f(H, 0)=0, \forall H, L$, and assume that $f_{i} \rightarrow \infty$ for $i \rightarrow 0, i=H, L$, and $f\left(N_{H}, N_{L}\right)<N_{H} \bar{w}_{H}+N_{L} \bar{w}_{L}$.

The interests of all firms are represented by an employers' federation seeking to maximize aggregate profits. Normalizing the price of the output good to unity, aggregate profits equal

$$
\Pi\left(w_{H}, w_{L}, H, L\right):=f(H, L)-w_{H} H-w_{L} L,
$$

where $w_{H}$ and $w_{L}$ denote the wages of the high- and low-skilled workers respectively. Differentiating the employers' objective function (profits) with respect to $w_{i}$ and $L_{i}$, holding the level of $\Pi$ constant at, say, $\pi$, reveals that their indifference curves (iso-profit curves) are increasing in $L_{i}$ until $f_{i}=w_{i}$, and decreasing

\footnotetext{
${ }^{10}$ If the industry consists of identical competitive firms employing a linearly homogeneous production function $\hat{f}: \mathbb{R}_{+}^{3} \rightarrow \mathbb{R}_{+}:(H, L, K) \mapsto \hat{f}(H, L, K)$, where $K$ denotes the level of all fixed factors of production, the aggregate production function coincides with firm-level production function. That is, $f$ may equally be interpreted as a firm's or as the industry's production function.
} 
afterwards:

$$
\left.\frac{d w_{i}}{d L_{i}}\right|_{\Pi=\pi}=\frac{f_{i}-w_{i}}{L_{i}}
$$

Note that

$$
w_{i}=f_{i}(H, L), \quad i=H, L
$$

characterizes the inverse aggregate labor-demand curve for type $i$-labour, given the employment level of the other type.

3.1. Bargaining with two independent labour unions. In case of separate bargains, where each group of labourers has formed its own union, the labour union of type $i$ labourer households, maximizes the aggregate utility of these $N_{i}$ households; or, in a framework of uncertainty, it maximizes the representative members' expected utility:

$$
\Psi_{i}\left(w_{i}, L_{i}\right):=L_{i} u_{i}\left(w_{i}\right)+\left(N_{i}-L_{i}\right) \bar{u}_{i},
$$

where $i=H, L$ denotes the mass of workers who obtain a job. ${ }^{11}$ Differentiation of the union's utility with respect to $w_{i}$ and $L_{i}$, holding the level of $\Psi_{i}$ constant at, say, $\psi_{i}$, shows that the union's indifference curves are downward sloping whenever $w_{i}$ is above the reservation wage $\bar{w}_{i}$ :

$$
\left.\frac{d w_{i}}{d L_{i}}\right|_{\Psi_{i}=\psi_{i}}=-\frac{u_{i}\left(w_{i}\right)-\bar{u}_{i}}{L_{i} u_{i}^{\prime}\left(w_{i}\right)}<0
$$

Gerber and Upmann (2006) have shown that in such a setting the negotiations between the firm/employers' association and a labour union constitute a bargaining problem in the sense of formal bargaining theory. For this reason we omit a corresponding proof and the translatation of our economic problem into the utility space, but study the bargaining problem in the wage-employment space directly.

We assume that both the wage rate and the employment level are determined by negotiations between the respective labor union and an employers' federation in an efficient way. That is, once an agreement is reached there is no room for renegotiations such that both parties can be made better off. Gerber and Upmann (2006) provide a couple of arguments in favour of efficient bargains. Although arguments may be found why negotiations may stop short of an efficient outcome, for

\footnotetext{
${ }^{11}$ In accordance with our previous terminology we will speak of $L_{i}$ as the number of employed workers.
} 
example, imperfect information and uncertainty, ${ }^{12}$ we shall follow their arguments here and assume efficient bargains.

Suppose that the negotiations between each labour union and the employers' federation take place simultaneously. Alternatively we may allow for sequential negotiations, where contracts may be cancelled and re-negotiated if, after a contract has been signed, the firm has subsequently agreed upon any contract with the other labour union different in one or the other aspect from the contract which has originally been assumed (or even signed). That is, we may think of sequential negotiations, if we were to allow for a multilateral right to give notice, effective if and when either party has subsequently signed a contract with another party which diverges from the contract which has initially been expected to materialize.

As is well known we can characterize the outcome of any efficient bargaining solution as the intersection of two curves in the employment-wage space. Focusing on the (asymmetric) Nash bargaining solution, the outcome of the negotiations between the firm/employers' association and the labour union of type $i$ labourers may be found as the point of intersection of the Nash curve with the Pareto curve. Both curves can be derived as the solution of the following maximization problem:

$$
\begin{aligned}
\max _{w_{i}, L_{i}} & {\left[\Psi_{i}\left(w_{i}, L_{i}\right)-N_{i} \bar{u}_{i}\right]^{\mu_{i}}\left[\Pi\left(w_{H}, w_{L}, H, L\right)\right]^{1-\mu_{i}} } \\
= & {\left[L_{i}\left(u_{i}\left(w_{i}\right)-\bar{u}_{i}\right)\right]^{\mu_{i}}\left[f(H, L)-w_{H} H-w_{L} L\right]^{1-\mu_{i}} }
\end{aligned}
$$

where $\mu_{i} \in[0,1]$ and $1-\mu_{i}$ represent the bargaining power of the labor union of group $i, i=H, L$, and the employers' federation, respectively. The first-order conditions of this maximization problem yield, for each bargaining problem, the Pareto curve and the Nash curve. The former is defined as the set of all employment-wage combinations such that both parties' indifference curves are tangent to each other,

$$
\begin{aligned}
\sigma_{H}\left(w_{H}\right) & :=\frac{w_{H} u_{H}^{\prime}\left(w_{H}\right)}{u_{H}\left(w_{H}\right)-\bar{u}_{H}}=\frac{w_{H}}{w_{H}-f_{H}(H, L)}, \\
\sigma_{L}\left(w_{L}\right) & :=\frac{w_{L} u_{L}^{\prime}\left(w_{L}\right)}{u_{L}\left(w_{L}\right)-\bar{u}_{L}}=\frac{w_{L}}{w_{L}-f_{L}(H, L)},
\end{aligned}
$$

\footnotetext{
${ }^{12}$ Due to the similarity of the formal analysis of the efficient bargaining model with the rightto-manage approach, the monopolistic union, and the insider-dominated union, which has been demonstrated by Creedy and McDonald (1991), Bayındır-Upmann and Raith (2003, 2005) and Upmann (2008), we may expect that an analysis similar to the present one holds for alternative labour market models as well.
} 
while the latter determines the bargained wage as the weighted average of the marginal and average productivity of labor, net of the cost of other factors, ${ }^{13}$

$$
\begin{aligned}
& w_{H}=\mu_{H} \frac{f(H, L)-w_{L} L}{H}+\left(1-\mu_{H}\right) f_{H}(H, L), \\
& w_{L}=\mu_{L} \frac{f(H, L)-w_{H} H}{L}+\left(1-\mu_{L}\right) f_{L}(H, L) .
\end{aligned}
$$

Taken together, equations (1) to (4) yield a system of four equations, the solution of which gives the negotiated wages $\hat{w}_{H}$ and $\hat{w}_{L}$ and the negotiated employment levels $\hat{H}$ and $\hat{L}$ - and correspondingly the equilibrium payoffs of the three parties: $\Psi_{H}\left(\hat{w}_{H}, \hat{H}\right), \Psi_{L}\left(\hat{w}_{L}, \hat{L}\right), \Pi\left(\hat{w}_{H}, \hat{w}_{L}, \hat{H}, \hat{L}\right)$.

It is illustrative to solve equations (3) and (4) for the negotiated wage rates, yielding

$$
\begin{aligned}
\hat{w}_{H} & =\hat{\eta}_{H} \frac{\hat{Y}-f_{L} \hat{L}}{\hat{H}}+\left(1-\hat{\eta}_{H}\right) f_{H}, \\
\hat{w}_{L} & =\hat{\eta}_{L} \frac{\hat{Y}-f_{H} \hat{H}}{\hat{L}}+\left(1-\hat{\eta}_{L}\right) f_{L},
\end{aligned}
$$

where $\hat{\eta}_{H}:=\frac{\mu_{H}\left(1-\mu_{L}\right)}{1-\mu_{H} \mu_{L}}$ and $\hat{\eta}_{L}:=\frac{\mu_{L}\left(1-\mu_{H}\right)}{1-\mu_{H} \mu_{L}}, \hat{\eta}_{H}, \hat{\eta}_{H} \in[0,1]$. Apparently, the negotiated wage rate of group $i$ is a weighted average of its marginal product, $f_{i}$, and the profit per worker (before labour cost) if the other factor were paid its marginal product. $\left(\hat{Y}-f_{-i} \hat{L}_{-i}\right) / \hat{L}_{i}$.

We may equivalently express the bargaining outcome in terms of wage shares, generally defined as $\omega_{i}:=w_{i} L_{i} / Y$. This is easily achieved by multiplying equations (3) and (4) by $\hat{L}_{i} / \hat{Y}$, arriving at

$$
\begin{aligned}
& \hat{\omega}_{H}=\mu_{H}\left(1-\hat{\omega}_{L}\right)+\left(1-\mu_{H}\right) \frac{\hat{H} f_{H}}{\hat{Y}}, \\
& \hat{\omega}_{L}=\mu_{L}\left(1-\hat{\omega}_{H}\right)+\left(1-\mu_{L}\right) \frac{\hat{L} f_{L}}{\hat{Y}}
\end{aligned}
$$

and solving for $\hat{\omega}_{H}$ and $\hat{\omega}_{L}$ yielding

$$
\begin{aligned}
\hat{\omega}_{H} & =\frac{\hat{H} f_{H}}{\hat{Y}}+\hat{\eta}_{H} \frac{\hat{Y}-\hat{L} f_{L}-\hat{H} f_{H}}{\hat{Y}} \\
\hat{\omega}_{L} & =\frac{\hat{L} f_{L}}{\hat{Y}}+\hat{\eta}_{L} \frac{\hat{Y}-\hat{L} f_{L}-\hat{H} f_{H}}{\hat{Y}} .
\end{aligned}
$$

These equations unveil that the negotiated wage share equals the competitive wage share $\frac{L_{i} f_{i}}{\hat{Y}}$ plus a fraction $\hat{\eta}_{i}$ of the share of the fixed factor if all factors were paid their marginal products $\frac{\hat{Y}-\hat{L} f_{L}-\hat{H} F_{H}}{\hat{Y}}$.

\footnotetext{
${ }^{13}$ It is straightforward to verify that the Pareto curve is increasing and the Nash curve is decreasing in the $\left(H, w_{H}\right)$-space, respectively in the $\left(L, w_{L}\right)$-space.
} 
CD Production Function. For both illustrative purposes and the sake of tractability, we elaborate the case where firms' technology can be characterized by a CobbDouglas production function,

$$
Y=f(H, L)=a H^{\alpha_{H}} L^{\alpha_{L}}, \quad \alpha_{H}, \alpha_{L} \in(0,1), \alpha_{H}+\alpha_{L}<1
$$

where $a:=K^{\alpha_{0}}$, with $\alpha_{0}:=1-\alpha_{H}-\alpha_{L}$, includes all fixed factors of production. With this specification of the production function we are able to derive more insights when the assumption of a general production technology brings about some ambiguity. In particular, with the assumption of a Cobb-Douglas production function, we are able to write down the wage shares, and thus the profit share, as a function of the parameters of the model. Substituting the Cobb-Douglas production function into equations (5) and (6) we obtain

$$
\begin{aligned}
\hat{\omega}_{H} & =\hat{\eta}_{H}\left(1-\alpha_{L}\right)+\left(1-\hat{\eta}_{H}\right) \alpha_{H}=\alpha_{H}+\hat{\eta}_{H}\left(1-\alpha_{H}-\alpha_{L}\right), \\
\hat{\omega}_{L} & =\hat{\eta}_{L}\left(1-\alpha_{H}\right)+\left(1-\hat{\eta}_{L}\right) \alpha_{L}=\alpha_{L}+\hat{\eta}_{L}\left(1-\alpha_{H}-\alpha_{L}\right) .
\end{aligned}
$$

Using the definition of $\hat{\eta}_{i}$, differentiation of $\hat{\omega}_{i}$ shows that the wage share of each group is increasing in its own but decreasing in the complimentary group's bargaining power.

Substituting the Cobb-Douglas production function into the Pareto curves, equations (1) and (2), these reduce to

$$
\begin{aligned}
\sigma_{H}\left(\hat{w}_{H}\right) & =\frac{\hat{\omega}_{H}}{\hat{\omega}_{H}-\alpha_{H}} \\
\sigma_{L}\left(\hat{w}_{L}\right) & =\frac{\hat{\omega}_{L}}{\hat{\omega}_{L}-\alpha_{L}} .
\end{aligned}
$$

Symmetric Bargaining Power. In the symmetric case where both unions have the same bargaining power, $\mu_{H}=\mu_{L}=\mu$, the wage shares simplify further to ${ }^{14}$

$$
\hat{\omega}_{H}=\frac{\alpha_{H}+\mu\left(1-\alpha_{L}\right)}{1+\mu}, \quad \hat{\omega}_{L}=\frac{\alpha_{L}+\mu\left(1-\alpha_{H}\right)}{1+\mu} .
$$

The equilibria of the two labour markets, one for the high- and one for the low-skilled workers, are depicted in Figures 1 and 2 for the following parameter specification: $f(H, L)=5 H^{0.505} L^{0.265}, \mu_{H}=\mu_{L}=\mu=1 / 2, N_{L}=1.1, N_{H}=1.7$,

\footnotetext{
${ }^{14}$ Note that the wage share of, say, group $H$ falls short of the wage share this group would have negotiated, if the other factor (group $L$ ) were paid its marginal product. In this case the wage share would have been $\hat{\omega}_{H}=\alpha_{H}+\mu\left(1-\alpha_{L}\right)$, which coincides with the result obtained by Bayındir-Upmann and Raith (2003), see eq. (10) therein.
} 


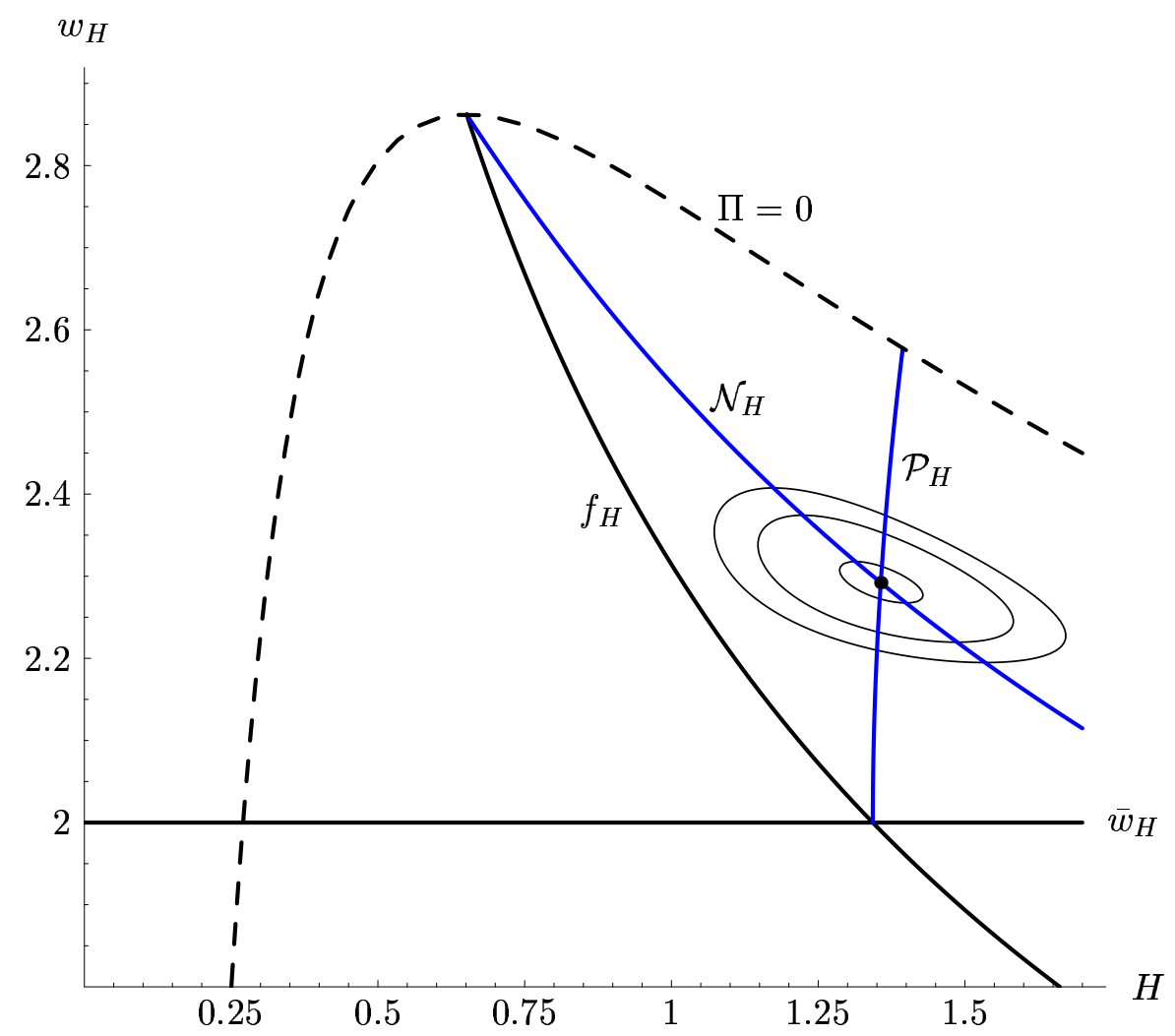

FiguRE 1. Equilibrium for the high-skilled workers

$u_{H}(w)=u_{L}(w)=\sqrt{w}$ and $\bar{u}_{H}=\bar{u}_{L}=\sqrt{2}$, implying $\bar{w}_{H}=\bar{w}_{L}=2$. For this specification the equilibrium values are:

$$
\begin{array}{ll}
\hat{w}_{H}=2.29216, & \hat{w}_{L}=2.53744, \quad \hat{H}=1.35661, \quad \hat{L}=0.71984, \\
\hat{\Psi}_{H}=2.53952, & \hat{\Psi}_{L}=1.68428, \quad \hat{\Pi}=0.409859, \hat{Y}=5.34599, \\
\hat{\omega}_{H}=0.581667, & \hat{\omega}_{L}=0.341667, \quad \hat{\omega}_{\Pi}=0.0766667 .
\end{array}
$$

The horizontal line at $w=2$ represents the reservation wage, $\bar{w}_{i}$; and the downward sloping line, the (respective) labour demand curve, $f_{i}$. At the point of intersection of these two curves, the Pareto curve, $\mathcal{P}_{i}$, originates and is upward sloping until it reaches the zero-profit curve (dashed curve). The downward sloping line between the labour demand curve and the zero-profit curve is the Nash curve, $\mathcal{N}_{i}$, which has a unique point of intersection with the Pareto curve characterizing the equilibrium of the (respective) labour market. The thin elliptic curves are lines of a constant Nash product.

3.2. Bargains with a united labour union. We now consider the case where both groups of labourers have formed a joint labour union which acts on behalf 


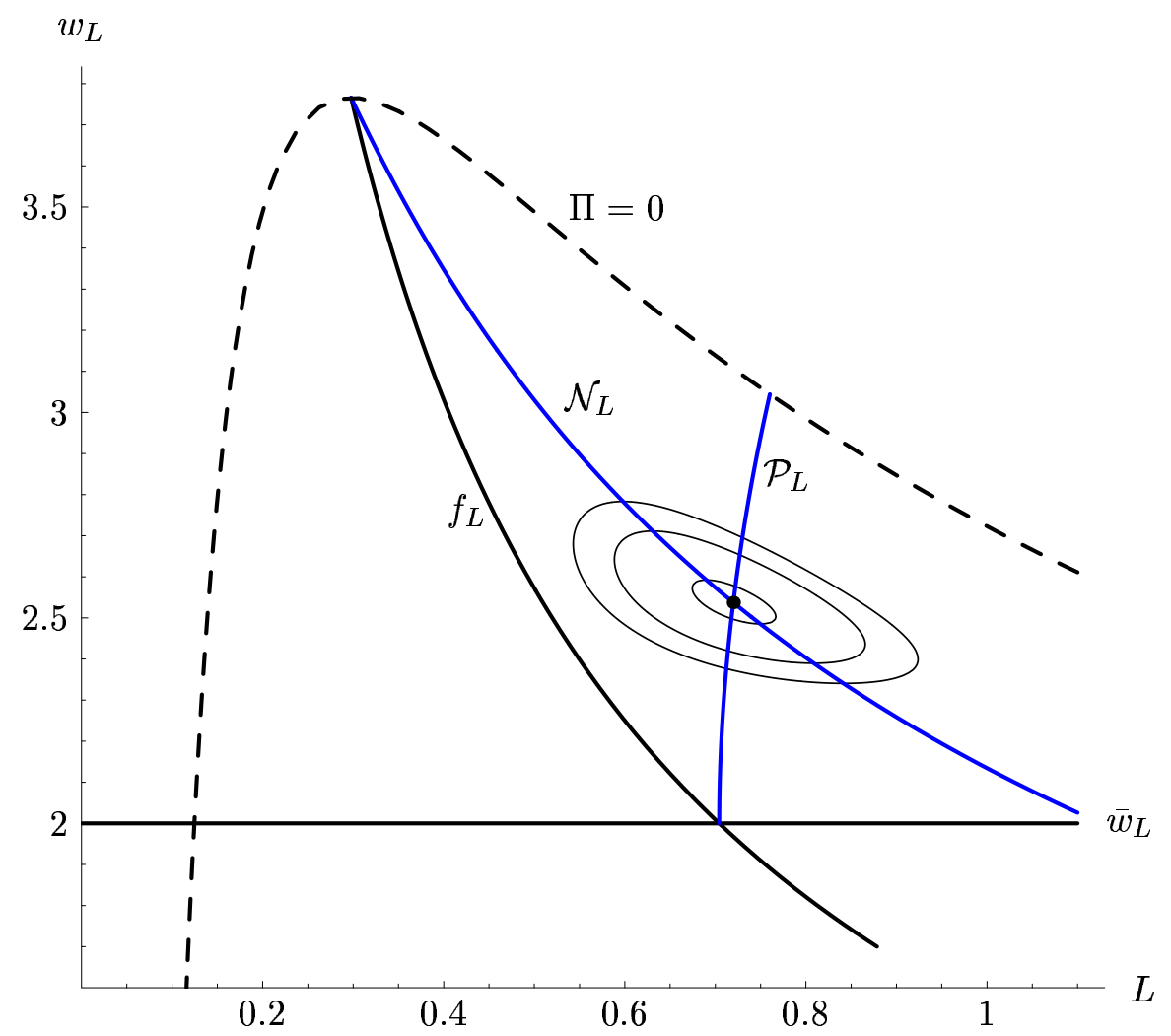

FiguRE 2. Equilibrium for the low-skilled workers

of all labourers' interests. In accordance with our previous specification of the objective functions of the two separate unions, we assume that the utility of this joint union is the sum of the utilities of its constituents: ${ }^{15}$

$$
\Psi\left(w_{H}, w_{L}, H, L\right):=H u_{H}\left(w_{H}\right)+\left(N_{H}-H\right) \bar{u}_{H}+L u_{L}\left(w_{L}\right)+\left(N_{L}-L\right) \bar{u}_{L} .
$$

In negotiations with the employers' federation, the parties bargain about $\left(w_{H}, w_{L}, H, L\right)$ simultaneously. The bargaining outcome is thus obtained as the solution of the maximization problem:

$$
\begin{aligned}
\max _{w_{H}, w_{L}, H, L} & {\left[\Psi\left(w_{H}, w_{L}, H, L\right)-N_{H} \bar{u}_{H}-N_{L} \bar{u}_{L}\right]^{\mu}[\Pi(w, L)]^{1-\mu} } \\
= & {\left[H\left(u_{H}\left(w_{H}\right)-\bar{u}_{H}\right)+L\left(u_{L}\left(w_{L}\right)-\bar{u}_{L}\right)\right]^{\mu}\left[f(H, L)-w_{H} H-w_{L} L\right]^{1-\mu}, }
\end{aligned}
$$

where $\mu$ is some weighted average of the bargaining power of the high- and the low-skilled workers, and we thus have $\mu \in\left[\min \left\{\mu_{H}, \mu_{L}\right\}, \max \left\{\mu_{H}, \mu_{L}\right\}\right] .{ }^{16}$ The

\footnotetext{
${ }^{15}$ This assumption is also standard in the literature, compare, for example, Davidson (1988) and Dowrick $(1989,1993)$.

${ }^{16}$ The bargaining power of the joint labour union may, for example, be equal to the arithmetic, the harmonic or the geometric mean of $\mu_{H}$ and $\mu_{L}$, but it may also be equal to either $\min \left\{\mu_{H}, \mu_{L}\right\}$
} 
first-order conditions of this maximization problem are given by

$$
\begin{aligned}
\sigma_{H}\left(w_{H}^{*}\right) & =\frac{w_{H}^{*}}{w_{H}^{*}-f_{H}\left(H^{*}, L^{*}\right)}, \\
\sigma_{L}\left(w_{L}^{*}\right) & =\frac{w_{L}^{*}}{w_{L}^{*}-f_{L}\left(H^{*}, L^{*}\right)}, \\
w_{H}^{*} & =\mu_{H}^{*} \frac{f\left(H^{*}, L^{*}\right)-w_{L}^{*} L^{*}}{H^{*}}+\left(1-\mu_{H}^{*}\right) f_{H}\left(H^{*}, L^{*}\right), \\
w_{L}^{*} & =\mu_{L}^{*} \frac{f\left(H^{*}, L^{*}\right)-w_{H}^{*} H^{*}}{L^{*}}+\left(1-\mu_{L}^{*}\right) f_{L}\left(H^{*}, L^{*}\right),
\end{aligned}
$$

where

$$
\mu_{H}^{*}:=\frac{\mu}{1+(1-\mu) R}, \quad \mu_{L}^{*}:=\frac{\mu}{1+(1-\mu) R^{-1}}, \quad \text { and } \quad R:=\frac{L^{*}\left(u_{L}\left(w_{L}^{*}\right)-\bar{u}_{L}\right)}{H^{*}\left(u_{H}\left(w_{H}^{*}\right)-\bar{u}_{H}\right)} .
$$

Carefully observe that conditions (12)-(15) coincide with the corresponding conditions (1)-(4) for separate negotiations, except that $\mu_{H}$ and $\mu_{L}$ have been replaced by $\mu_{H}^{*}$ and $\mu_{L}^{*}$, respectively, which we call notional bargaining powers for future reference. This is a subtle, though important difference, which crucially affects the negotiated wage rates: In the case of a joint labour union, the (relative) weights attributed to the marginal and the average products of labour are modified, compared with the weights in case of separate bargaining. This modification consists of two components: Firstly, the (relative) bargaining power of the joint labour union is some weighted average of those of the two single unions, $\mu_{H}$ respectively $\mu_{L}$, which are now replaced by $\mu$. This implies, ceteris paribus, that the post-unification bargaining power is lower for the labour union with the higher pre-unification bargaining power, and higher for the other one. Secondly, the fact that the joint labour union takes into account the utilities of both groups of employees results in the appearance of the additional term $(1-\mu) R$ and $(1-\mu) R^{-1}$ in the denominator of $\mu_{H}^{*}$ and $\mu_{L}^{*}$, respectively. Since $R$ depends on the equilibrium values of $H, L, w_{H}$ and $w_{L}$, the notional bargaining powers $\mu_{H}^{*}$ and $\mu_{L}^{*}$ are endogenous as well.

Note also that

$$
\mu \geq \mu_{H}^{*} \text { and } \mu \geq \mu_{L}^{*}
$$

because $(1-\mu) R$ and $(1-\mu) R^{-1}$ are both non-negative. The notional bargaining powers can thus not be larger than the actual bargaining power of the joint labour union - and they are strictly smaller if $R \in(0,+\infty)$. In other words, the notional bargaining power of the joint union is for each group of workers lower than the average bargaining power of the autonomous labour unions. This suggests that

$\left.\overline{\text { or } \max \left\{\mu_{H}, \mu_{L}\right.}\right\}$. How $\mu$ is composed of $\mu_{H}$ and $\mu_{L}$ should reflect the mode how the unification of the two labour unions is pursued. But this is not an issue here. 
'on average' the Nash equation is shifted downwards when compared with separate bargains, which in turn implies, ceteris paribus, a lower negotiated wage rate 'on average'. - Whether or not the each group of labourers actually benefits or suffers from the bargains of the joint union is the issue of the next section. For the moment, it is instructive to solve equations (14) and (15) for the negotiated wage rates, yielding

$$
\begin{aligned}
& w_{H}^{*}=\eta_{H}^{*} \frac{Y^{*}-f_{L} L^{*}}{H^{*}}+\left(1-\eta_{H}^{*}\right) f_{H}, \\
& w_{L}^{*}=\eta_{L}^{*} \frac{Y^{*}-f_{H} H^{*}}{L^{*}}+\left(1-\eta_{L}^{*}\right) f_{L},
\end{aligned}
$$

where $\eta_{H}^{*}:=\frac{\mu_{H}^{*}\left(1-\mu_{L}^{*}\right)}{1-\mu_{H}^{*} \mu_{L}^{*}}=\frac{\mu}{1+R}$ and $\eta_{L}^{*}:=\frac{\mu_{L}^{*}\left(1-\mu_{H}^{*}\right)}{1-\mu_{H}^{*} \mu_{L}^{*}}=\frac{\mu R}{1+R}$. Equivalently expressing the bargaining outcome in terms of wage shares we obtain

$$
\begin{aligned}
\omega_{H}^{*} & =\frac{H^{*} f_{H}}{Y^{*}}+\eta_{H}^{*} \frac{Y^{*}-L^{*} f_{L}-H^{*} f_{H}}{Y^{*}}, \\
\omega_{L}^{*} & =\frac{L^{*} f_{L}}{Y^{*}}+\eta_{L}^{*} \frac{Y^{*}-L^{*} f_{L}-H^{*} f_{H}}{Y^{*}} .
\end{aligned}
$$

Note that the wage share of each group is increasing in $\eta_{i}^{*}, i=H, L$. Similar to negotiations with separate labour unions, the negotiated wage rate of group $i$ is a weighted average of its marginal product, $f_{i}$, and the profit per worker (before labour cost) if the other factor were paid its marginal product, $\left(Y-f_{-i} L_{-i}\right) / L_{i}$; but the weights of the two factors differ: $\hat{\eta}_{i}$ has been replaced by $\eta_{i}^{*}$ under joint bargains.

CD Production Function. For the special case of a Cobb-Douglas production function equations (16) and (17) may be written as

$$
\begin{aligned}
& \omega_{H}^{*}=\eta_{H}^{*}\left(1-\alpha_{L}\right)+\left(1-\eta_{H}^{*}\right) \alpha_{H}=\alpha_{H}+\frac{\left(1-\alpha_{H}-\alpha_{L}\right) \mu}{1+R}, \\
& \omega_{L}^{*}=\eta_{L}^{*}\left(1-\alpha_{H}\right)+\left(1-\eta_{L}^{*}\right) \alpha_{L}=\alpha_{L}+\frac{\left(1-\alpha_{H}-\alpha_{L}\right) \mu R}{1+R} .
\end{aligned}
$$

For our specification given on page 11 the equilibrium values for a joint labour union are:

$$
\begin{aligned}
& w_{H}^{*}=2.2876, \quad w_{L}^{*}=2.2876, \quad H^{*}=1.33849, \quad L^{*}=0.702375, \\
& \Psi_{H}^{*}=2.53569, \quad \Psi_{L}^{*}=1.62466, \quad \Pi^{*}=0.606665, Y^{*}=5.27535, \\
& \omega_{H}^{*}=0.580422, \quad \omega_{L}^{*}=0.304578, \quad \omega_{\Pi}^{*}=0.115 \text {. }
\end{aligned}
$$

This outcome is illustrated in Figures 3 and 4 and contrasted with the outcome under independent negotiations. It is important to realize that the equilibrium values imply that the notional bargaining powers in fact decrease in the course of unification: $\mu_{H}^{*}=0.396078<1 / 2$ and $\mu_{L}^{*}=0.256039<1 / 2$. 


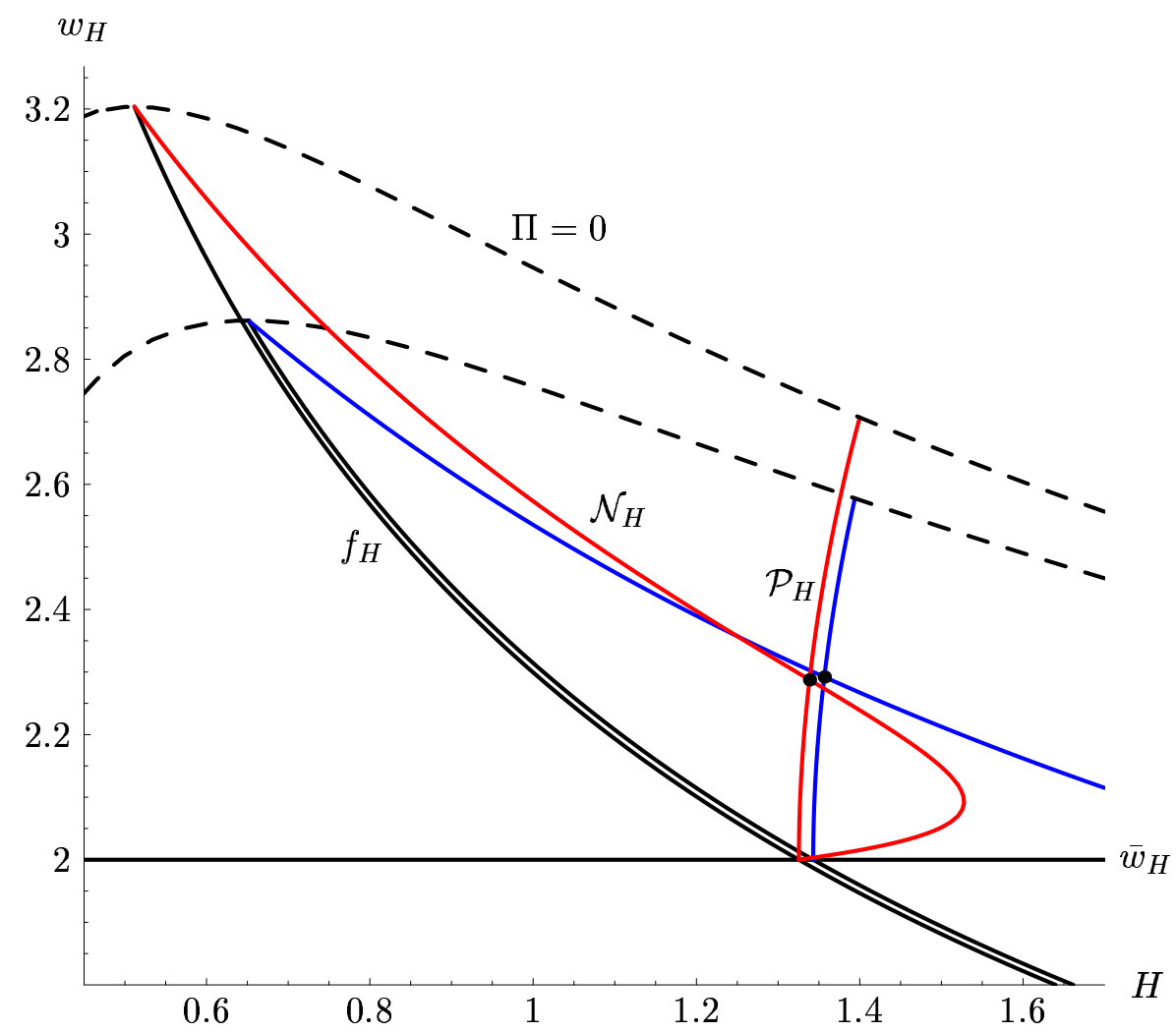

FIGURE 3. Separate and joint negotiations for the high-skilled workers

3.3. Who may benefit from splitting the joint labour union? We have characterized the equilibria of the labour market under both organizational structures of the labour force. It is now natural to ask whether separate bargains are in the interest of each group of workers, or separate negotiations may be favourable for at least one group. For a split of the joint labour union to be beneficial for an employed labourer, his/her wage rate must be higher under separate negotiations when compared with joint negotiations. An alternative to a comparison of the wage rates is the comparison of the bargained wage shares. While the first approach ignores any employment effects, the latter takes the point of view of the labour union as a group. - We shall investigate both variables.

We have already seen that the Pareto curves under separate and joint bargains coincide. Thus, if joint negotiations were to lead to the same employment levels as under separate negotiations, the negotiated wage rates must coincide as well. For this reason our main interest is directed towards an inspection of the Nash curves under both organizational structures. We know from equations (3) and (4) and (14) and (15), that the Nash curves under joint negotiations coincide with those under separate negotiations, except that $\mu_{H}$ and $\mu_{L}$ have been replaced by $\mu_{H}^{*}$ 


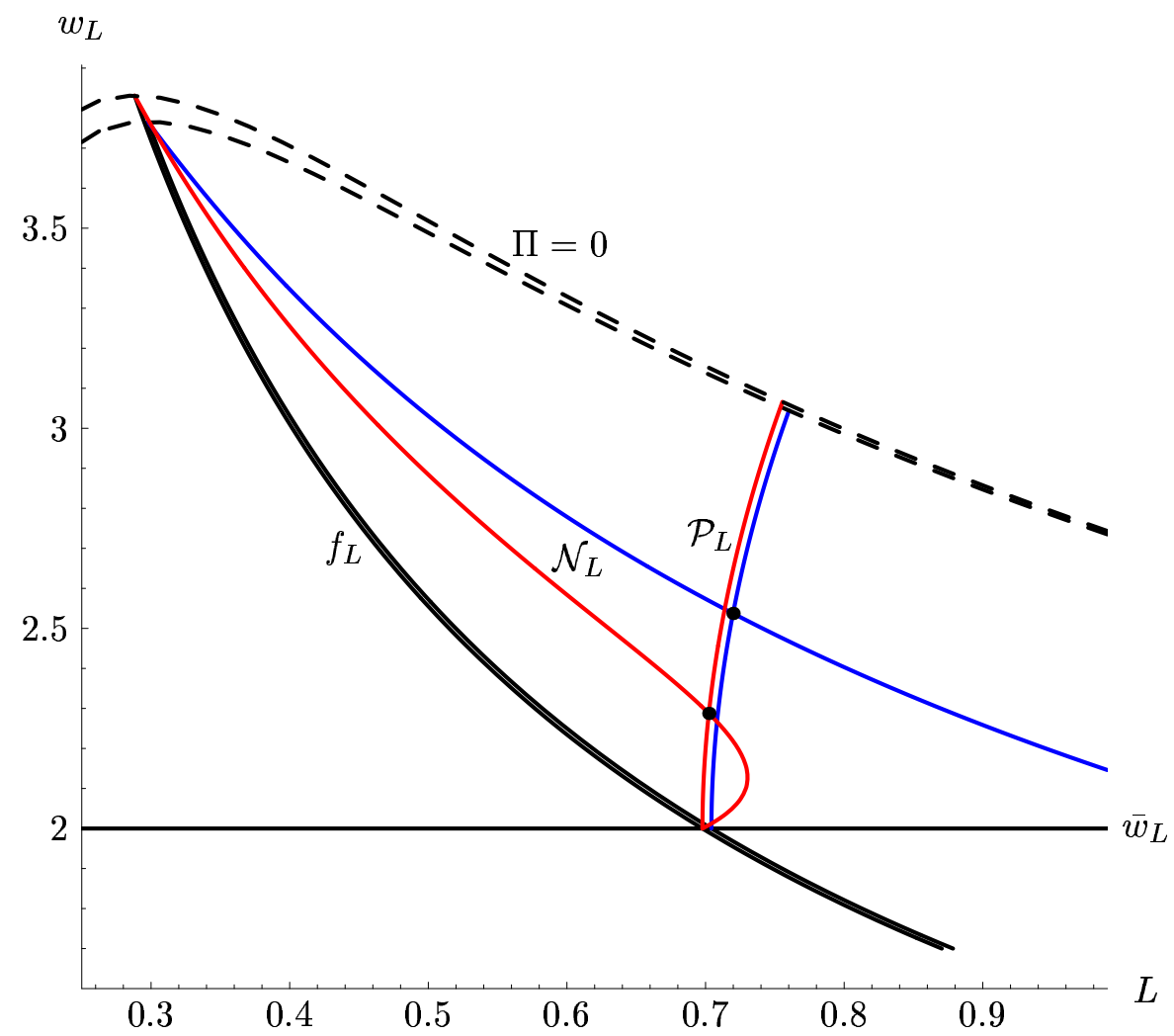

FiguRE 4. Separate and joint negotiations for the low-skilled workers

and $\mu_{L}^{*}$, respectively. That is, the relative weights attached to the average and the marginal product of labour differ under both scenarios. More precisely, if for, say, group $H$ workers we have $\mu_{H}>\mu_{H}^{*}$, the wage formula under separate negotiations puts a higher relative weight onto the average product of labour than does the wage formula under joint negotiations. For this reason the Nash curve is ceteris paribus shifted downwards under joint negotiations, if

$$
\mu_{H}>\mu_{H}^{*} \quad \Leftrightarrow \quad \mu_{H}>\mu \frac{1+\mu_{H} R}{1+R} .
$$

Similarly we obtain for the group of low-skilled workers:

$$
\mu_{L}>\mu_{L}^{*} \quad \Leftrightarrow \quad \mu_{L}>\mu \frac{1+\mu_{L} R^{-1}}{1+R^{-1}}
$$

Since the fractions on the right hand sides of (20) and (21) are both (weakly) smaller than one, and since $\min \left\{\mu_{H}, \mu_{L}\right\} \leq \mu \leq \max \left\{\mu_{H}, \mu_{L}\right\}$, it must be true that at least the larger of $\left\{\mu_{H}, \mu_{L}\right\}$ exceeds its 'starred' value $\mu_{i}^{*}$. For that reason we find: 
Proposition 1. For at least one group of labourers the actual bargaining power under separate negotiations exceeds its notional bargaining power under joint negotiations.

Consequently, a higher value is associated with the average product of labour in wage equations (3) and (4) when compared with (14) and (15), respectively. Due to concavity of $f$ the average product of labour exceeds its marginal, implying that ceteris paribus the Nash curve under separate negotiations lies above the Nash curve under joint negotiations, for at least one group of employees.

It is noteworthy that conditions (20) and (21) may be fulfilled simultaneously, and thus both Nash curves may be shifted downwards under joint bargains.

Corollary 1. It may happen that the actual bargaining powers of both groups of labourers are higher under separate bargains when compared with their corresponding notional bargaining powers under joint negotiations.

This can best be seen for the special case of equal bargaining power. In the symmetric case where both unions have the same bargaining power, $\mu_{H}=\mu_{L}=\mu$, conditions (20) and (21) are clearly both fulfilled, implying that joint negotiations lead, ceteris paribus, to a downward shift of the Nash curves for both labour unions. Since the Pareto curve has positive slope, a downward shift of the Nash curve implies both a lower wage rate and a lower employment level.

In general, however, the wage and employment levels of both labourer groups vary as either Nash curve shifts. This implies that the Nash curve of, say, type $H$ labourers is affected by a change of both the employment level and the wage rate of type $L$ labourers. In order to see this, totally differentiate the Nash curve equation of high skilled labourers, equation (3), for some given level of $H$, yielding

$$
H d w_{H}=\left(Y-w_{L} L-f_{H} H\right) d \mu_{H}+\left(\left(1-\mu_{H}\right) H f_{H L}-\mu_{H}\left(w_{L}-f_{L}\right)\right) d L-\mu_{H} L d w_{L}
$$

Since the first bracket term is positive, a higher bargaining power shifts the Nash curve upwards, an effect which we have already seen. The second bracket term is composed of two effects: The first term reflects the fact that a higher demand for the low-skilled workers positively (negatively) affects the marginal product of the high-skilled workers if both factors are complements (substitutes) in production; and, clearly, any increase in the productivity of labour positively affects the Nash curve. ${ }^{17}$ However, there is also a negative cost effect of the $L$-type labour market

\footnotetext{
${ }^{17}$ If both types of labour are complements, a reduction in the employment of type $L$ labour reduces the demand for type $H$ labour as well. A leftward shift of the labour demand curve, however, also implies a leftward movement of the Pareto curve, further strengthening the negative employment effect while mitigating, and possibly (over-)compensating, the negative wage effect.
} 
equilibrium onto the potential profits per $H$-type worker. When the wage rate of type $L$ workers exceeds their marginal product, any increase in $L$ reduces the available net profits which may be negotiated between the firm and type $H$ workers. A similar argument applies to an increase of the wage rate paid to type $L$ workers. A higher wage $w_{L}$ reduces the amount which can be divided by the firm owners and $H$-type workers. In sum, while a higher (notional) bargaining power leads ceteris paribus to an upward shift of the Nash curve, second-order effects on the Nash curve of type $H$ workers originate from varying levels of $L$ and $w_{L}$. A higher wage rate paid to the $L$-type workers leads to a downward shift of this curve, while the effect of a higher employment level of $L$-type labour is ambiguous if both factors are complements, but is negative if they are substitutes. In sum, one might argue that the Nash curve for each group makes a downward move, if previously independent labour unions unite and start bargaining collectively. Yet, as we may infer from Figure 3 the effect of unification may be ambiguous: The Nash curve under joint negotiations lies above the original Nash curve for low values of $H$, but below for high values.

Thus far we have considered possible shifts in the Nash curve, but it is equally important, at least, to realize that the shape of the Nash curve under joint bargains differs from the shape of the Nash curves under separate bargains as well. In particular, we shall see that while the Nash curve under separate bargains is monotonously decreasing and lies strictly above the labour-demand except at its origin on the zero-profit curve, neither of both properties holds under joint bargains. In order to explore the shape of the Nash curve in more detail, we firstly determine its endpoints and then elaborate its slope. Consider the Nash-curve for type $H$ labourers, equation (14), for some fixed tuple $\left(L, w_{L}\right)$ with $L>\bar{L}, w_{L}>\bar{w}_{L}$. We know that, by definition, $\left(\bar{H}, \bar{w}_{H}\right)$ is the point of intersection of the labour demand curve with the labour supply curve (reservation wage) and thus satisfies $\bar{w}_{H}=f_{H}(\bar{H}, L)$. In addition, define $\left(H^{0}, w_{H}^{0}\right)$ as the point of intersection of the labour demand curve with the zero-profit curve, that is, the pair $\left(H^{0}, w_{H}^{0}\right)$ is implicitly defined by $w_{H}^{0}=f_{H}\left(H^{0}, L\right)$ and $f\left(H^{0}, L\right)-w_{L} L-w_{H}^{0} H^{0}=0$. (And analogously we define $\left(L^{0}, w_{L}^{0}\right)$.)

Lemma 1. Under joint negotiations the end points of the Nash curve for type $H$ and type $L$ labourers are given by $\left(H^{0}, w_{H}^{0}\right)$ and $\left(\bar{H}, \bar{w}_{H}\right)$, and $\left(L^{0}, w_{L}^{0}\right)$ and $\left(\bar{L}, \bar{w}_{L}\right)$ respectively.

Proof: Consider a pair $\left(H, w_{H}\right)$ on the labour demand curve, i. e., satisfying $w_{H}=f_{H}(H, L)$. Substituting this pair into the Nash curve, equation (14), this

As a consequence, even if we had a, ceteris paribus, constant Nash curve for one type of labourers, the guaranteed downward shift of the Nash curve of the other type suffices to decrease both equilibrium employment levels. 
equation collapses to $\mu_{H}^{*}\left(f(H, L)-w_{L} L-w_{H} H\right)=0$, which is fulfilled if either $f(H, L)-w_{L} L-w_{H} H=0$ or $\mu_{H}^{*}=0$. The former is satisfied by $\left(H^{0}, w_{H}^{0}\right)$; the latter, by $\left(\bar{H}, \bar{w}_{H}\right)$, since $R \rightarrow+\infty$ and thus $\mu_{H}^{*} \rightarrow 0$, if $w_{H} \rightarrow \bar{w}_{H}$. Corresponding arguments apply to the Nash curve for type $L$ labourers.

Lemma 1 shows that each group's Nash curve under joint bargains originates at the point of intersection of the labour demand curve with the zero-profit curve and ends at the point of intersection of the labour demand curve with the reservation wage level, i.e., at the competitive equilibrium of the labour market. Thus, while under both separate and joint negotiations the respective Nash curves originate at $\left(H^{0}, w_{H}^{0}\right)$ respectively $\left(L^{0}, w_{L}^{0}\right)$, they behave differently beyond the starting point. In particular, under separate negotiations each Nash curve monotonically decreases, approaching the $w_{i}$-axis for $L_{i} \rightarrow+\infty$. Under joint negotiations, however, each Nash curve terminates at the competitive labour market equilibrium $\left(\bar{L}_{i}, \bar{w}_{i}\right)$. Moreover, it is apparent from equations (3) and (14), respectively (4) and (15), that, apart from the endpoints, the Nash curve lies strictly above the labour demand curve under both labour market scenarios. It thus remains to investigate the shape of the Nash curve between its endpoints more deliberately. Doing this, we arrive at the following result.

Lemma 2. The Nash curve under joint negotiations, equation (14) [respectively equation (15)], may have a positive slope at $\left(\bar{H}, \bar{w}_{H}\right)$ [respectively at $\left.\left(\bar{L}, \bar{w}_{L}\right)\right]$. If so, it is backward bending at some $L_{i}>\bar{L}_{i}$.

Proof: Consider the slope of the $H$-type Nash curve. To this end we regard $w_{L}$ and $L$ as fixed and re-write equation (14) as

$$
w_{H}=\mu_{H}^{*}\left(R\left(H, w_{H}\right)\right) \frac{f(H, L)-w_{L} L}{H}+\left(1-\mu_{H}^{*}\left(R\left(H, w_{H}\right)\right)\right) f_{H}(H, L),
$$

suppressing $L$ and $w_{L}$ as arguments of $R$. Using the derivatives

$$
\frac{d \mu_{H}^{*}}{d R}=-\frac{1-\mu}{\mu}\left(\mu_{H}^{*}\right)^{2}, \quad \frac{\partial R}{d H}=-\frac{R}{H}, \quad \frac{\partial R}{d w_{H}}=-\frac{u_{H}^{\prime}\left(w_{H}\right)}{u_{H}\left(w_{H}\right)-\bar{u}_{H}} R
$$

we obtain

$$
\frac{\partial w_{H}}{\partial H}=\frac{\left(1-\mu_{H}^{*}\right) f_{H H}-\frac{w_{H}-f_{H}}{H}\left(1-\mu_{H}^{*} \frac{1-\mu}{\mu} R\right)}{1-\mu_{H}^{*} \frac{1-\mu}{\mu} R \frac{w_{H}-f_{H}}{w_{H}} \sigma_{H}} .
$$

Since $\mu_{H}^{*} \frac{1-\mu}{\mu} R=\frac{(1-\mu) R}{1+(1-\mu) R} \in(0,1)$, and since the bargained wage (weakly) exceeds the marginal product of labour, $w_{h} \geq f_{H}$, the numerator is negative. The denominator, however, may be of either sign. In particular, it is negative in the neighbourhood of the Pareto curve, for substituting $\frac{w_{H}}{w_{H}-f_{H}}=\sigma_{H}$ the denominator collapses to $1-\mu_{H}^{*} \frac{1-\mu}{\mu} R$, which is positive, as we have just argued. However, the right-limit derivative of the Nash curve at $\left(\bar{H}, \bar{w}_{H}\right)$ is positive. To see this, 
recall from the proof of Lemma 1 that with $w_{H} \rightarrow \bar{w}_{H}$ we have $R \rightarrow+\infty$ and thus $\mu_{H}^{*} \rightarrow 0$; moreover, it is easy to see that $R \mu_{H}^{*} \rightarrow \mu /(1-\mu)$. It thus remains to investigate the limit of $\frac{w_{H}-f_{H}}{w_{H}} \sigma_{H}$. Using $w_{H}-f_{H}=\mu_{H}^{*} \frac{\bar{\Pi}(H)}{H}$, where $\bar{\Pi}(H):=f(H, L)-w_{L} L-f_{H}(H, L) H$, and the definitions of $\sigma_{H}$ and $R$, we arrive at $\frac{w_{H}-f_{H}}{w_{H}} \sigma_{H}=R \mu_{H}^{*} \bar{\Pi}(H) \frac{u_{H}^{\prime}\left(w_{H}\right)}{L\left(u_{L}\left(w_{L}\right)-\bar{u}_{L}\right)}$. Taking the limit $H \rightarrow \bar{H}$ yields

$$
\lim _{H \rightarrow \bar{H}} \frac{w_{H}-f_{H}}{w_{H}} \sigma_{H}=\frac{\mu}{1-\mu} \bar{\Pi}(\bar{H}) \frac{u_{H}^{\prime}\left(\bar{w}_{H}\right)}{L\left(u_{L}\left(w_{L}\right)-\bar{u}_{L}\right)} .
$$

Putting the pieces together we arrive at

$$
\lim _{H \rightarrow \bar{H}} \frac{\partial w_{H}}{\partial H}=\frac{f_{H H}(\bar{H}, L)}{1-\frac{\mu}{1-\mu} \bar{\Pi}(\bar{H}) \frac{u_{H}^{\prime}\left(\bar{w}_{H}\right)}{L\left(u_{L}\left(w_{L}\right)-\bar{u}_{L}\right)}} .
$$

To complete the proof we have to show that the right hand side may be positive. Using our specification 3.1, cf. page 11, we find $\lim _{H \rightarrow \bar{H}} \frac{\partial w_{H}}{\partial H}=0.1831$.

Since the Nash curve is falling at its origin, i. e., in the neighbourhood of $L_{i}^{0}$, but may be increasing at $\bar{L}_{i}$, it follows from Lemma 2 that the Nash curve may be backward bending at some $L_{i}>\bar{L}_{i}$. This is exactly the case displayed in Figures 3 and 4 , on pages 15 and 16 respectively.

The next result follows immediately from our preceding analysis.

Lemma 3. If the Nash curve for group $i$ under joint bargains is not backward bending, the bargaining outcome for group $i$ equals the competitive equilibrium.

However, it follows from the objective function of the joint labour union, $\Psi$, that if one group of labourers is paid its marginal product, the other group receives a wage rate above its competitive level, for otherwise the value of the maximized Nash product would have been equal to zero. Thus, we find:

Lemma 4. Under joint bargains at most one group is paid its marginal product.

Now, depending on the shape of the Nash curve(s) there are three possible candidates for an equilibrium.

Proposition 2. Under joint bargains there are three candidates for an equilibrium of the labour market:

- $\left(H, w_{H}\right)>\left(\bar{H}, \bar{w}_{H}\right)$ and $\left(L, w_{L}\right)=\left(\bar{L}, \bar{w}_{L}\right)$

- $\left(H, w_{H}\right)=\left(\bar{H}, \bar{w}_{H}\right)$ and $\left(L, w_{L}\right)>\left(\bar{L}, \bar{w}_{L}\right)$

- $\left(H, w_{H}\right)>\left(\bar{H}, \bar{w}_{H}\right)$ and $\left(L, w_{L}\right)>\left(\bar{L}, \bar{w}_{L}\right)$ 
Thus, we may either have "a competitive equilibrium plus an interior equilibrium" or a "fully interior equilibrium". Since under separate bargains, each group succeeds in negotiating a wage-employment pair exceeding the competitive equilibrium, a group which is paid it marginal product under joint negotiations is always better off under separate negotiations.

Proposition 3. For any corner solution at least one group of labourers benefits from constituting its own independent, professional labour union.

It is important to realize that corner solutions are by no means pathological outcomes. In order to see this, we return to a Cobb-Douglas production function.

$C D$ Production Function. It is illustrative to consider the case of a Cobb-Douglas production function. In this case, we are able to show that at least one group of labourers benefits in terms of the wage share from leaving the joint union and constituting its own professional labour union; and under reasonable conditions, this is true for both groups of labourers. In other words, at least one group of labourers suffers from a unification of the two professional labour unions and the formation of an industry union.

In order to see this, we compare equations (7) and (8) with (18) and (19), respectively. Comparing $\hat{\omega}_{H}$ with $\omega_{H}^{*}$ shows that bargaining with separate labour unions is beneficial to the high-skilled workers if

$$
\hat{\omega}_{H}>\omega_{H}^{*} \quad \Leftrightarrow \quad \hat{\eta}_{H}>\eta_{H}^{*} \quad \Leftrightarrow \mu<\frac{\mu_{H}\left(1-\mu_{L}\right)}{1-\mu_{H} \mu_{L}}(1+R) .
$$

Correspondingly, we obtain for the wage share of the low-skilled workers:

$$
\hat{\omega}_{L}>\omega_{L}^{*} \quad \Leftrightarrow \quad \hat{\eta}_{L}>\eta_{L}^{*} \quad \Leftrightarrow \quad \mu<\frac{\mu_{L}\left(1-\mu_{H}\right)}{1-\mu_{H} \mu_{L}} \frac{1+R}{R} .
$$

Equal Bargaining Power. Subsequently we focus on the special case when both unions have equal bargaining power, i.e., $\mu_{H}=\mu_{L}=\mu$. In this case, condition (22) reduces to

$$
\mu=\mu_{H}<R,
$$

for the high-skilled workers; and condition (23), to

$$
\mu=\mu_{L}<1 / R,
$$

for the low-skilled workers. (Recall that $R$ is evaluated at $\left(w_{H}^{*}, w_{L}^{*}, H^{*}, L^{*}\right)$.) Note that $\mu>\max \{R, 1 / R\}$ is impossible, as $\mu \in[0,1]$. This implies that, irrespective of the particular parameters chosen, it is always beneficial for at least one group of labourers to abandon the joint labour union and to constitute a group specific union, given equal bargaining power of both labourer groups, $\mu_{H}=\mu_{L}=\mu$. 
Proposition 4. Let both labourer groups have the same bargaining power, $\mu_{H}=$ $\mu_{L}=\mu$. Under the assumption of a Cobb-Douglas production function, it is beneficial, in terms of the wage share, for at least one group of labourers to constitute its own (professional) labour union.

Note that an increase in the wage rate for workers of type $i$ is equivalent to an increase in their wage share. This equivalence follows from the fact that the Pareto-curve for group $i$ labourers is characterized by

$$
\sigma_{i}\left(w_{i}\right)=\frac{\omega_{i}}{\omega_{i}-\alpha_{i}},
$$

under both separate and joint negotiations (cf. eqs (9) and (10)). Since the right hand side of this equation is decreasing in $\omega_{i}$ and since $\sigma_{i}$ is, by assumption, a decreasing function, $\omega_{i}$ and $w_{i}$ move parallelly. That is, the bargained wage increases if the wage share does so, and vice versa. An increase in $w_{i}$ is thus equivalent to an increase in $\omega_{i}$.

Corollary 2. Under the assumptions of Proposition 4, it is beneficial, in terms of the wage rate, for at least one group of labourers to constitute its own (professional) labour union.

Also note that with equal bargaining power $\mu_{i}>\mu_{i}^{*}$ holds for both groups simultaneously, implying that under separate negotiations the bargained wage is closer (in relative terms) to the average product than to the marginal product of labour. Moreover, it is noteworthy that both conditions may be met simultaneously, i.e., that $\mu<\min \{R, 1 / R\}$. This is visualized in Figure 5. As long as the excess utilities under joint bargaining are not 'too different', and thus $R=\left(L\left(u_{L}\left(w_{L}\right)-\bar{u}_{L}\right)\right) /\left(H\left(u_{H}\left(w_{H}\right)-\bar{u}_{H}\right)\right)$ is not 'too large' or 'too small', a split of the joint union into two separate ones is beneficial for both labourer groups, in terms of their wage shares, for (almost) any value of $\mu$. If, for example, the bargaining power is split equally between the firm and the (joint) union, i. e., $\mu=1-\mu=1 / 2$, any labour market equilibrium for which $1 / 2<R<2$ provides incentives for both labourer groups to constitute its own labour union.

That is, the weight attached to the average product of labour is larger under separate bargaining than under joint bargaining. In other words, given equal bargaining power of both groups of workers, the effective bargaining power of a labour union acting on behalf of both groups of workers is lower than the bargaining power of each group in separate negotiations. This is a remarkable result, as one might expect labour unions to become more powerful when uniting to a joint labour union. But this is not the case. Rather, two separate (small) labour unions are more effective in bargaining for a higher wage share than a joined labour union. 


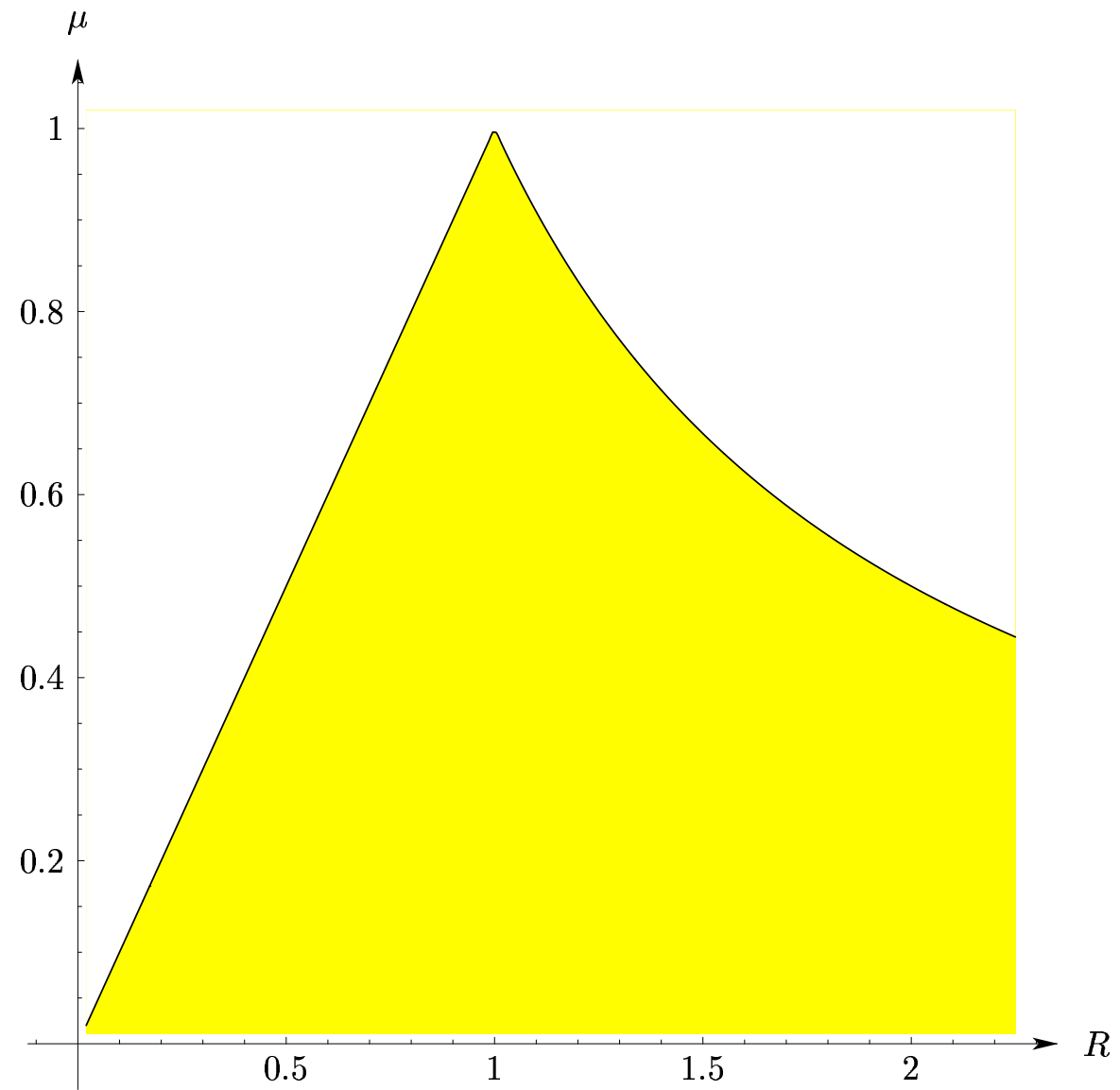

FiguRE 5. Area where both labourer groups benefit from separate bargains

When the two types of labour are sufficiently complementary each group acting independently of the other can virtually paralyse the firm. The marginal contribution of each group is then the entire surplus associated with the firm's activity. Thus, when the two types of labour are organized separately each union can force the firm to bargain over the division of the entire surplus. In this sense the firm's surplus is bargained for twice - by each union in turn (Horn and Wolinsky, 1988, p. 493).

As a consequence, there may be little what is worse for a firm (or an employers' federation) than to bargain with a labour union acting on behalf of all workers' interest - but bargaining with two separate labour unions actually is. A doublemonopoly of two independent labour unions is even worse for a firm than a 'simple' monopoly of one large labour union.

Corollary 3. Under sufficient symmetry, both groups of labourers benefit, in terms of both the wage share and the wage rate, from constituting their own (professional) labour unions. 


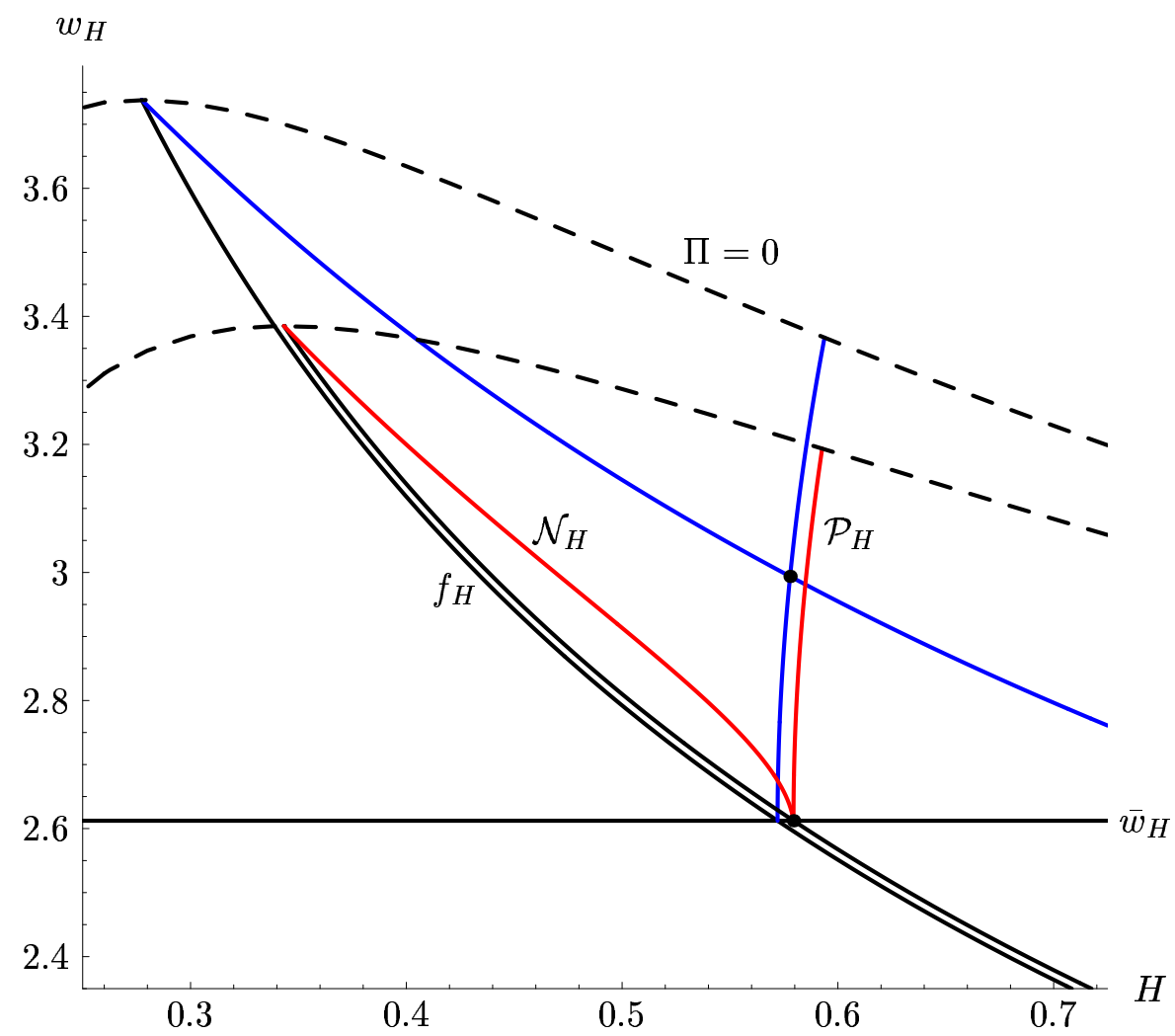

FiguRE 6. Second example: Separate and joint negotiations for the high-skilled workers

It remains to show that small perturbations of our model may bring about corner solutions, which can thus not be considered as pathological outcomes of a mis-specified model.

A Second Example: Corner Solutions. Our second example demonstrates that the Nash curve need not be backward bending, and thus a corner solution $\left(\bar{L}_{i}, \bar{w}_{i}\right)$ may in fact emerge. To this end, we apply the same specification as in our original example (see page 11), apart from the following modifications: $u_{H}(w)=(7 / 8) \sqrt{w}$, $u_{L}(w)=\sqrt{w}$ and $\bar{u}_{H}=\bar{u}_{L}=\sqrt{2}$, implying $\bar{w}_{H}=2.61224$ and $\bar{w}_{L}=2$. Finally, we set $N_{L}=1, N_{H}=1$.

Under separate bargains, the equilibria for the high- and the low-skilled workers are given by:

$$
\begin{array}{lll}
\hat{w}_{H}=2.99385, & \hat{w}_{L}=2.53744, \quad \hat{H}=0.577846, & \hat{L}=0.400475, \\
\hat{\Psi}_{H}=1.47187, & \hat{\Psi}_{L}=1.48579, \quad \hat{\Pi}=0.228021, & \hat{Y}=2.97418, \\
\hat{\omega}_{H}=0.581667, & \hat{\omega}_{L}=0.341667, & \hat{\omega}_{\Pi}=0.0766667 .
\end{array}
$$




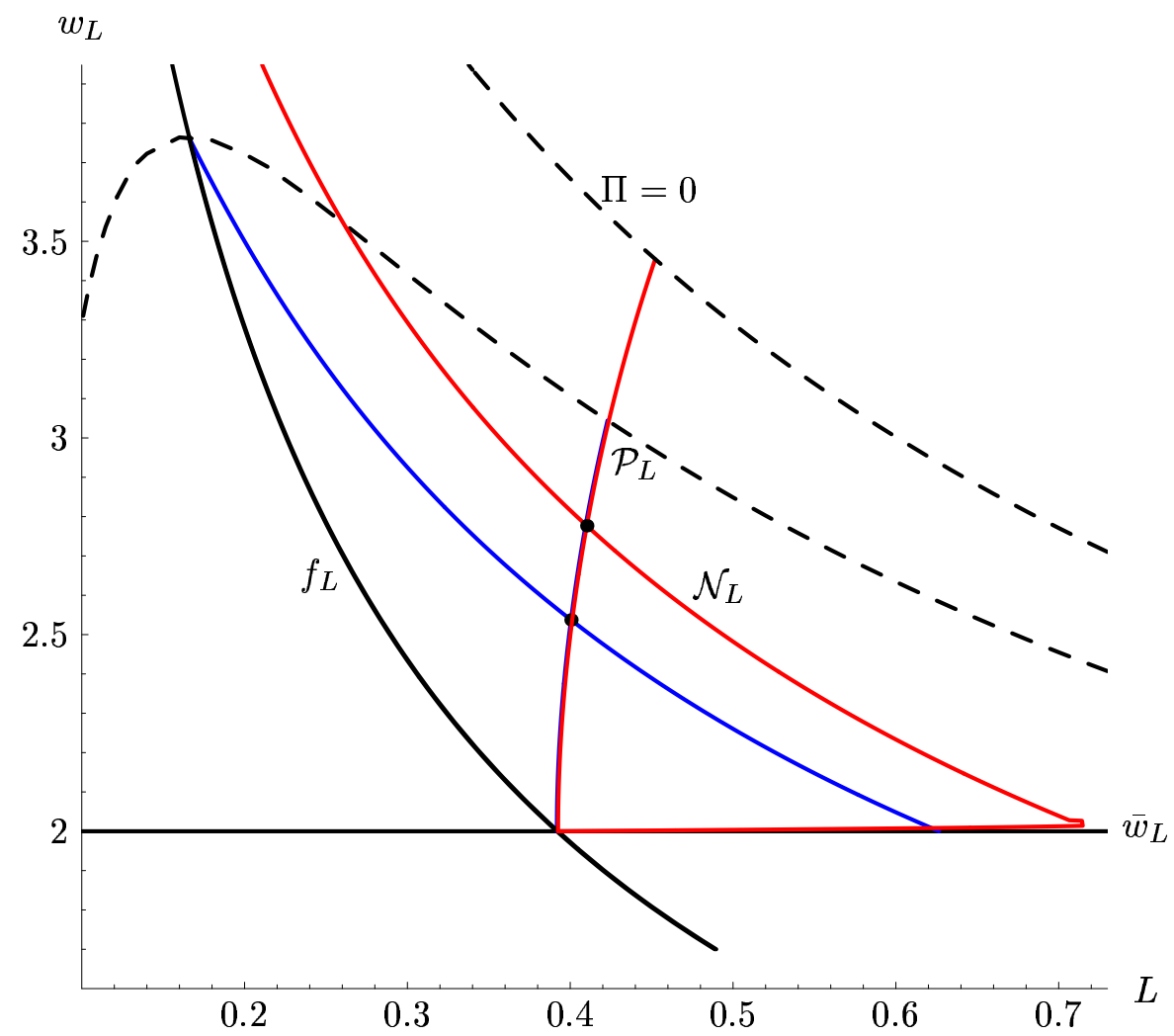

FiguRE 7. Second example: Separate and joint negotiations for the low-skilled workers

The labour market equilibrium for a joint labour union is given by:

$$
\begin{array}{lll}
w_{H}^{*}=2.61224, & w_{L}^{*}=2.77676, & H^{*}=0.579424, \quad L^{*}=0.410171, \\
\Psi_{H}^{*}=1.41421, & \Psi_{L}^{*}=1.51764, & \Pi^{*}=0.34468, \quad Y^{*}=2.99722, \\
\omega_{H}^{*}=0.505, & \omega_{L}^{*}=0.38, & \omega_{\Pi}^{*}=0.115 .
\end{array}
$$

This outcome is illustrated in Figures 3 and 4 and contrasted with the outcome under independent negotiations.

\section{Conclusion}

The starting point of our paper was that within the last decade we observed, in Germany at least, two opposing trends in the formation of labour unions. On the one hand, independent labour unions united in order to constitute powerful industry unions; on the other hand, specialized groups of employees formed their own independent labour unions, or left former tariff-unions. Due to the overwhelming economic importance of labour markets and labour market contracts, it is both a 
politically explosive, economically important, and theoretically challenging question whether labour unions should unite or stand alone. In this paper we tackle this intriguing question and ask whether it is in the interest of two different groups of employees to maintain their own independent professional labour unions, or to form a joint industry labour union. And if it is, under which conditions?

Applying the (asymmetric) Nash bargaining solution to the firm-union negotiations, we commence our analysis of a potential merger of two independent trade unions with an inspection of the Pareto and the (so-called) Nash curves before and after the merger. While a merger does not affect the shape of the Pareto curves, it alters the shape of the Nash curves significantly: For each group the after-merger Nash curve ends up at the competitive wage-employment contract. If it has a positive slope at this point, there are two candidates of an equilibrium: an 'interior' solution where both groups obtain a wage rate and an employment level exceeding the respective competitive levels; and a 'corner' solution where a joint labour union 'disregards' the interest of one group of labourers in equilibrium. In this case, the disregarded group is employed up to the competitive level and receives the competitive wage. Since an independent labour union arrives at a wage rate and an employment level in excess of the competitive levels, the disregarded group faces a strong incentive to leave the joint labour union (or not to join it). Moreover, if the slope of Nash curve is negative at the competitive wage-employment contract (for one group of labourers), a corner solution is the only candidate for an equilibrium. In this case, a joint union is not in the interest of this group of labourers (at least). Yet, even if the interests of both groups are acknowledged in equilibrium, in the sense that both receive a wage above the competitive level, a merger is arguably unstable: Under mild conditions, it is beneficial for at least one group of labourers to constitute its own (professional) labour union.

Which of these cases actually occurs depends on the productivities of the two groups of labourers. With asymmetries in productivity, firm-union negotiations lead to corner solutions, while with a sufficient degree of symmetry, a merger may be unfavourable for both groups of labourers, even though interior solutions are negotiated. These results are consistent with the finding of Gürtzgen (2003), that the consequences of merger activities (centralization) depend, among others, on the technical relationship between types of labour in production. Also, our results confirm two central conclusions of Horn and Wolinsky (1988), p. 485: When the two types of labour are sufficiently strong complements, then in equilibrium the two types are likely to be organized in two separate unions; and when there are two independent unions their behaviour is more aggressive. The latter result explains why the 'effective' bargaining power of each group tends to be lower after the merger when compared with the pre-merger level. 
This also explains our final result that the profit share is always higher under joint negotiations. The firm thus favours bargaining with a joint labour union, over bargaining with independent craft-specific labour unions. Loosely speaking, a strong industry union is a 'bad thing' for the firm. But two independent (professional) labour unions are even worse! - Considering the most recent conflict between the GDL and the Deutsche Bahn, we conclude that both the chairman of the GDL, Manfred Schell, and the CEO of the Deutsche Bahn, Hartmut Mehdorn, were justified in fighting for, respectively, against a separate wage agreement for the engine drivers. 


\section{References}

Th. Bayındır-Upmann and M. G. Raith. Should high-tax countries pursue revenueneutral ecological tax reforms? European Economic Review, 47:41-60, 2003.

Th. Bayındır-Upmann and M. G. Raith. Unemployment and pollution: Is one policy suited for two problems? The Economic Record, 81:378-393, 2005.

S. Boeters. Green tax reform and employment: The interaction of profit and factor taxes. FinanzArchiv, 60(2):222-239, 2004.

R. T. Buchanan. Merger waves in British unionism. Industrial Relations Journal, 2(5):37-44, 1974.

R. T. Buchanan. Mergers in British unions 1949-79. Industrial Relations Journal, 3(12):40-49, 1981.

J. T. Campling and Grant Michelson. Trade union mergers in British and Australian television broadcasting. British Journal of Industrial Relations, 35(2): 215-242, 1997.

G. N. Chaison. A note on union merger trends, 1900-1978. Industrial and Labor Relations Review, 34(1):114-120, 1980.

J. Creedy and I. M. McDonald. Models of trade union behaviour: A synthesis. The Economic Record, 67:346-359, 1991.

C. Davidson. Multiunit bargaining in oligopolistic industries. Journal of Labor Economics, 6(3):397-422, 1988.

S. Dowrick. Union-oligopoly bargaining. Economic Journal, 99(398):1123-1142, 1989.

S. Dowrick. Enterprise bargaining, union structure and wages. Economic Record, 69(207):393-404, 1993.

A. Gerber and Th. Upmann. Bargaining solutions at work: Qualitative differences in policy implications. Mathematical Social Sciences, 52:162-175, 2006.

G. Griffin and V. Scarcebrook. Trends in mergers of federally registered unions 1904-1986. Journal of Industrial Relations, 31:257-262, 1989.

N. Gürtzgen. Revisiting the impact of union structures on wages: Integrating different dimensions of centralization. Labour, 17(4):519-542, 2003.

H. Horn and A. Wolinsky. Worker substitutability and patterns of unionisation. Economic Journal, 98(391):484-497, 1988.

B. Keller. Union formation through merger: The case of Ver.di in Germany. British Journal of Industrial Relations, 43(2):209-232, 2005.

I. M. McDonald and R. M. Solow. Wage bargaining and employment. American Economic Review, 71:896-908, 1981.

T. Morris. Trade union mergers and competition in British banking. Industrial Relations Journal, 2(17):129-140, 1986. 
Th. Upmann. A positive analysis of labor-market institutions and tax reforms. International Tax and Public Finance, forthcoming, 2008.

J. Waddington. Trade union mergers. In D. Cox, editor, Facing the Future, pages 105-146. Nottingham University Press, 1992. 


\section{CESifo Working Paper Series}

for full list see www.cesifo-group.org/wp

(address: Poschingerstr. 5, 81679 Munich, Germany, office@cesifo.de)

2353 Michael Kaganovich and Itzhak Zilcha, Alternative Social Security Systems and Growth, July 2008

2354 Keith Blackburn, Kyriakos C. Neanidis and M. Emranul Haque, Corruption, Seigniorage and Growth: Theory and Evidence, July 2008

2355 Edward Castronova, A Test of the Law of Demand in a Virtual World: Exploring the Petri Dish Approach to Social Science, July 2008

2356 Harald Badinger and Peter Egger, GM Estimation of Higher-Order Spatial Autoregressive Processes in Cross-Section Models with Heteroskedastic Disturbances, July 2008

2357 Wolfgang Buchholz and Jan Schumacher, Discounting the Long-Distant Future: A Simple Explanation for the Weitzman-Gollier-Puzzle, July 2008

2358 Luca Anderlini, Leonardo Felli and Alessandro Riboni, Statute Law or Case Law?, July 2008

2359 Guglielmo Maria Caporale, Davide Ciferri and Alessandro Girardi, Are the Baltic Countries Ready to Adopt the Euro? A Generalised Purchasing Power Parity Approach, July 2008

2360 Erkki Koskela and Ronnie Schöb, Outsourcing of Unionized Firms and the Impacts of Labour Market Policy Reforms, July 2008

2361 Francisco Alvarez-Cuadrado and Ngo Van Long, A Permanent Income Version of the Relative Income Hypothesis, July 2008

2362 Gabrielle Demange, Robert Fenge and Silke Uebelmesser, Financing Higher Education and Labor Mobility, July 2008

2363 Alessandra Casarico and Alessandro Sommacal, Labor Income Taxation, Human Capital and Growth: The Role of Child Care, August 2008

2364 Antonis Adam, Manthos D. Delis and Pantelis Kammas, Fiscal Decentralization and Public Sector Efficiency: Evidence from OECD Countries, August 2008

2365 Stefan Voigt, The (Economic) Effects of Lay Participation in Courts - A Cross-Country Analysis, August 2008

2366 Tobias König and Andreas Wagener, (Post-)Materialist Attitudes and the Mix of Capital and Labour Taxation, August 2008 
2367 Ximing Wu, Andreas Savvides and Thanasis Stengos, The Global Joint Distribution of Income and Health, August 2008

2368 Alejandro Donado and Klaus Wälde, Trade Unions Go Global!, August 2008

2369 Hans Gersbach and Hans Haller, Exit and Power in General Equilibrium, August 2008

2370 Jan P.A.M. Jacobs and Jan-Egbert Sturm, The Information Content of KOF Indicators on Swiss Current Account Data Revisions, August 2008

2371 Oliver Hülsewig, Johannes Mayr and Timo Wollmershäuser, Forecasting Euro Area Real GDP: Optimal Pooling of Information, August 2008

2372 Tigran Poghosyan and Jakob de Haan, Determinants of Cross-Border Bank Acquisitions in Transition Economies: A Latent Class Analysis, August 2008

2373 David Anthoff and Richard S.J. Tol, On International Equity Weights and National Decision Making on Climate Change, August 2008

2374 Florian Englmaier and Arno Schmöller, Reserve Price Formation in Online Auctions, August 2008

2375 Karl Farmer, Birgit Friedl and Andreas Rainer, Effects of Unilateral Climate Policy on Terms of Trade, Capital Accumulation, and Welfare in a World Economy, August 2008

2376 Monika Bütler, Stefan Staubli and Maria Grazia Zito, The Role of the Annuity’s Value on the Decision (Not) to Annuitize: Evidence from a Large Policy Change, August 2008

2377 Inmaculada Martínez-Zarzoso, The Impact of Urbanization on $\mathrm{CO}_{2}$ Emissions: Evidence from Developing Countries, August 2008

2378 Brian Roberson and Dmitriy Kvasov, The Non-Constant-Sum Colonel Blotto Game, August 2008

2379 Ian Dew-Becker, How Much Sunlight Does it Take to Disinfect a Boardroom? A Short History of Executive Compensation Regulation, August 2008

2380 Cécile Aubert, Oliver Falck and Stephan Heblich, Subsidizing National Champions: An Evolutionary Perspective, August 2008

2381 Sebastian Buhai, Miguel Portela, Coen Teulings and Aico van Vuuren, Returns to Tenure or Seniority?, August 2008

2382 Erkki Koskela and Jan König, Flexible Outsourcing, Profit Sharing and Equilibrium Unemployment, August 2008

2383 Torberg Falch and Justina AV Fischer, Does a Generous Welfare State Crowd out Student Achievement? Panel Data Evidence from International Student Tests, September 2008 
2384 Pedro Gomes and François Pouget, Corporate Tax Competition and the Decline of Public Investment, September 2008

2385 Marko Koethenbuerger, How Do Local Governments Decide on Public Policy in Fiscal Federalism? Tax vs. Expenditure Optimization, September 2008

2386 Ronald McKinnon and Gunther Schnabl, China’s Exchange Rate Impasse and the Weak U.S. Dollar, September 2008

2387 Yan-Leung Cheung, Yin-Wong Cheung and Alan T.K. Wan, A High-Low Model of Daily Stock Price Ranges, September 2008

2388 Louis Eeckhoudt and Harris Schlesinger, Changes in Risk and the Demand for Saving, September 2008

2389 Carsten Hefeker and Blandine Zimmer, Uncertainty and Fiscal Policy in an Asymmetric Monetary Union, September 2008

2390 Jay Pil Choi and Byung-Cheol Kim, Net Neutrality and Investment Incentives, September 2008

2391 Marcel Gérard, Financing Bologna, the Internationally Mobile Students in European Higher Education, September 2008

2392 Annette Alstadsæter and Knut Reidar Wangen, Corporations' Choice of Tax Regime when Transition Costs are Small and Income Shifting Potential is Large, September 2008

2393 António Afonso and Christophe Rault, 3-Step Analysis of Public Finances Sustainability: the Case of the European Union, September 2008

2394 Betsey Stevenson and Justin Wolfers, Economic Growth and Subjective Well-Being: Reassessing the Easterlin Paradox, September 2008

2395 Bernhard Eckwert and Itzhak Zilcha, Private Investment in Higher Education: Comparing Alternative Funding Schemes, September 2008

2396 Øystein Foros, Hans Jarle Kind and Jan Yngve Sand, Slotting Allowances and Manufacturers’ Retail Sales Effort, September 2008

2397 Mohammad Reza Farzanegan, Illegal Trade in the Iranian Economy: Evidence from a Structural Model, September 2008

2398 Olivier Bos, Charity Auctions for the Happy Few, September 2008

2399 Robert S. Chirinko and Debdulal Mallick, The Marginal Product of Capital: A Persistent International Puzzle, September 2008

2400 Ben D’Exelle and Arno Riedl, Elite Capture, Political Voice and Exclusion from Aid: An Experimental Study, September 2008 
2401 Torben M. Andersen and Joydeep Bhattacharya, On Myopia as Rationale for Social Security, September 2008

2402 Fabienne Llense, French CEO Compensations: What is the Cost of a Mandatory Upper Limit?, September 2008

2403 Valentina Bosetti, Carlo Carraro, Alessandra Sgobbi and Massimo Tavoni, Delayed Action and Uncertain Targets. How Much Will Climate Policy Cost?, September 2008

2404 Robert G. Chambers, Rolf Färe, Shawna Grosskopf and Michael Vardanyan, Generalized Quadratic Revenue Functions, September 2008

2405 Leonidas Enrique de la Rosa, Overconfidence in a Career-Concerns Setting, September 2008

2406 Marcus Drometer and Johannes Rincke, The Design of Political Institutions: Electoral Competition and the Choice of Ballot Access Restrictions in the United States, September 2008

2407 Markku Lanne and Helmut Lütkepohl, Stock Prices and Economic Fluctuations: A Markov Switching Structural Vector Autoregressive Analysis, September 2008

2408 Thomas L. Brewer, International Energy Technology Transfers for Climate Change Mitigations, September 2008

2409 Alexander Kemnitz, Native Welfare Losses from High Skilled Immigration, September 2008

2410 Xavier Vives, Strategic Supply Function Competition with Private Information, September 2008

2411 Fabio Padovano and Roberto Ricciuti, The Political Competition-Economic Performance Puzzle: Evidence from the OECD Countries and the Italian Regions, September 2008

2412 Joan Costa-Font and Mireia Jofre-Bonet, Body Image and Food Disorders: Evidence from a Sample of European Women, September 2008

2413 Thorsten Upmann, Labour Unions - To Unite or to Separate?, October 2008 